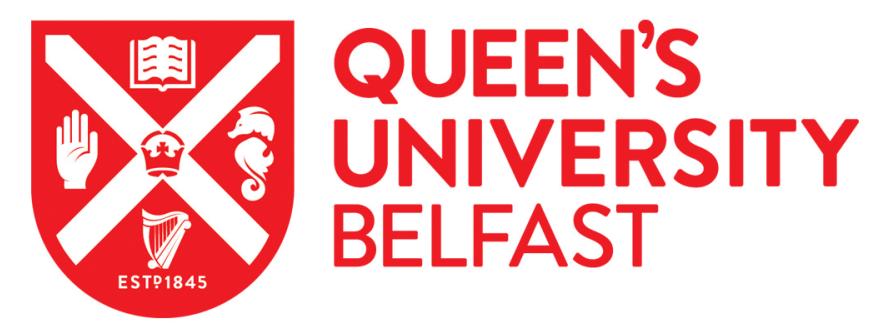

\title{
The development of asymmetries in past and future thinking
}

Burns, P., McCormack, T., Jaroslawska, A., Fitzpatrick, A., McGourty, J., \& Caruso, E. (2019). The development of asymmetries in past and future thinking. Journal of Experimental Psychology: General, 148(2), 272-288. https://doi.org/10.1037/xge0000464

Published in:

Journal of Experimental Psychology: General

Document Version:

Peer reviewed version

Queen's University Belfast - Research Portal:

Link to publication record in Queen's University Belfast Research Portal

Publisher rights

(c) 2018 American Psychological Association. This work is made available online in accordance with the publisher's policies. Please refer to any applicable terms of use of the publisher.

\section{General rights}

Copyright for the publications made accessible via the Queen's University Belfast Research Portal is retained by the author(s) and / or other copyright owners and it is a condition of accessing these publications that users recognise and abide by the legal requirements associated with these rights.

Take down policy

The Research Portal is Queen's institutional repository that provides access to Queen's research output. Every effort has been made to ensure that content in the Research Portal does not infringe any person's rights, or applicable UK laws. If you discover content in the Research Portal that you believe breaches copyright or violates any law, please contact openaccess@qub.ac.uk. 
The Development of Asymmetries in Past and Future Thinking

\begin{tabular}{|c|c|c|}
\hline Patrick Burns $^{1}$ & a McCormack ${ }^{1}$ & Agnieszka Jaroslawska ${ }^{2}$ \\
\hline Áine Fitzpatrick ${ }^{1}$ & Jemma McGourty ${ }^{1}$ & Eugene Caruso $^{3}$ \\
\hline
\end{tabular}

\section{Author note.}

Patrick Burns, Teresa McCormack, Áine Fitzpatrick and Jemma McGourty, School of Psychology, Queen’s University Belfast, Agnieszka Jaroslawska, School of Philosophy, Psychology, and Language Sciences, University of Edinburgh, Eugene Caruso, Booth School of Business, University of Chicago.

This research was supported by a research grant from the Economic and Social Sciences Research Council, UK, Grant No. ES/N000900/1. Portions of the data presented in this article were presented at the 39th annual meeting of the Cognitive Science Society, London, July, 2017, at an annual meeting of the European Society for Philosophy and Psychology, Hertfordshire, UK, August, 2017, and at a meeting of the British Psychological Society Developmental Section, Stratford-upon-Avon, UK, September, 2017.

Correspondence concerning this article should be sent to Patrick Burns, School of Psychology, Queen's University Belfast, Belfast, UK, BT71NN. Telephone: ++44 2890974623; Email: p.burns@qub.ac.uk 


\begin{abstract}
A number of striking temporal asymmetries have been observed in the way that adults think about the past and the future: experiences in the future tend to be more valued than those in the past, feel closer in subjective time, and elicit stronger emotions. Three studies explored the development of these temporal asymmetries for the first time with children and adolescents. Evidence of past/future asymmetry in subjective time emerged from 4-to-5-years of age. Evidence of past/future asymmetry in emotion was clearly observable from 6-to-7years of age. Evidence of past/future asymmetry in value emerged latest in development and was uncorrelated with judgments of emotion and subjective distance at all ages. We consider the underlying causes of these asymmetries, and discuss the potential relations among them.
\end{abstract}

Keywords: Time, past, future, temporal asymmetries, emotion 
The Development of Asymmetries in Past and Future Thinking

The minds of adults are frequently occupied by thoughts that are not about the hereand-now (Berntsen \& Jacobsen, 2008; Busby Grant \& Walsh, 2016; D’Argembeau, Renaud, \& Van der Linden, 2011; Klinger \& Cox, 1987). A considerable body of research in neuropsychology, cognitive psychology, and more recently in the field of decision-making, has focused on adults' ability to engage in what has been termed mental time travel (e.g., Boyer, 2008; Hassabis, Kumaran, \& Maguire, 2007; Peters \& Büchel, 2011; Schacter et al., 2012; Suddendorf \& Corballis, 1997, 2007; Tulving, 1983). Although this body of research has sometimes emphasized the similarity of past and future mental time travel (Addis, Wong \& Schacter, 2007; Okuda, 2007; Suddendorf \& Busby, 2005; Szpunar, Chan, \& McDermott, 2008), theorists have typically argued that the brain systems underlying mental time travel have specifically evolved to enable humans to prepare for the future (Boyer, 2008; Schacter, Addis, \& Buckner, 2007; Suddendorf \& Corballis, 2007). Indeed, the literature on mindwandering has suggested that adults usually spend more time thinking about the future than the past (Baird, Smallwood, \& Schooler, 2011; Busby Grant \& Walsh, 2016; Jason, Schade, Furo, Reichler, \& Brickman, 1989; Smallwood \& Schooler, 2015).

In line with the idea that people are typically more concerned about the future than the past, a small but growing body of research in social psychology has demonstrated that adults show a series of past-future asymmetries in their judgments and attitudes that suggest that they are future-biased. For example, adults tend to report feeling stronger emotions when thinking about an event in the future compared to the same event in the past, and value future events more than past ones (Caruso, 2010; Caruso, Gilbert, \& Wilson, 2008; Caouette, Wohl, \& Peetz, 2012; Van Boven \& Ashworth, 2007). Indeed, there has been considerable discussion amongst moral philosophers and metaphysicians about future bias (e.g., Brink, 2011; Dougherty, 2011, 2015; Greene \& Sullivan, 2015; Hare, 2007, 2013; Parfit, 1984; 
Sullivan, in press; Tarsney, 2017), focusing on its rationality and whether it is compatible with views of the nature of time that are prevalent in philosophy and theoretical physics that do not distinguish ontologically between past and future (Greene \& Sullivan, 2015; Hare, 2007; Suhler \& Callender, 2012; Yehezkel, 2014).

One idea that has featured across these different areas of psychology and philosophy is that it is adaptive to focus on and care about future events more than past ones (Hare, 2013; Suddendorf \& Corballis, 2007; Suhler \& Callender, 2012), because one can either prepare for or determine the former but not the latter. However, although the suggestion that humans have evolved to be focused on and biased towards the future rather than the past is plausible, we know surprisingly little about whether the tendency to care more about the future is present early in development. The assumption that children do not start out with concepts of the past, present, and future and that development involves a gradual shift away from a focus simply on the here-and-now is a long-standing one (Fraisse, 1963; Guyau 1890/1988; Piaget, 1969; see McCormack, 2015, for review). Moreover, the broad claim that across development children and adolescents become more oriented towards and concerned with the future, instead of being merely preoccupied by the present, has been cashed out in a variety of ways by developmental psychologists (e.g., Chen \& Vazsonyi, 2011; Greene, 1986; Nurmi, 1991; Steinberg et al., 2009). However, as yet it is not known whether children show the same sort of cognitive biases regarding the future versus the past that are apparent in adults. On the basis of claims about the evolutionary basis of such biases, one might predict that these temporal differences would be present once children moved beyond simply thinking about the here-and-now. The aim of this paper is to provide the first empirical study of temporal asymmetries in children's past and future judgments, in order to directly examine the time course over which such asymmetries emerge. Studying such asymmetries developmentally can also shed light on the nature of these phenomena and the inter-relations among them. 


\section{Temporal Asymmetries}

An emerging body of research with adults explores the cognitive, affective, and motivational differences between past and future thinking. Of particular relevance to the phenomenon of future bias are studies that have examined temporal value asymmetry (TVA; Caruso, Gilbert, \& Wilson, 2008). TVA refers to people's tendency to value future experiences more than equivalent experiences in the equidistant past. For instance, Caruso et al. (2008; Study 1$)^{1}$ found that participants believed they should receive considerably more payment for five hours' work that they imagined they would complete in one month's time in the future (US\$125.04) relative to the payment a separate group of participants believed they should receive for the same work that they imagined having completed one month ago (US\$62.20). Indeed, Caruso et al. found participants placed more value on future experiences compared to past experiences across a range of hypothetical and real-life scenarios. This was also the case for a positively valenced event: University students asked to rate how much they would be or would have been prepared to pay in order to extend their reading week break made higher valuations in advance of the break than subsequent to it. Caruso et al.'s findings have been replicated in a North American sample of adults (Guo, Ji, Spina, \& Zhang, 2012).

On the face of it, such asymmetries in valuation are surprising and may seem irrational. Indeed, if the same participants are asked to make the past and future event valuations, the asymmetry disappears, presumably because participants believe it would not seem sensible to provide different valuations. How should TVA be explained? Caruso (Caruso, 2010; Caruso et al., 2008) puts forward a specific suggestion: that people value the future more because they experience greater affect when imagining future events compared to past events (for a similar line of argument, see Callender, 2017; Suhler \& Callender, 2012). It is this emotional experience that then influences the valuations people make. Accordingly,

\footnotetext{
${ }^{1}$ The majority of participants in this study were Harvard undergraduates. The ethnicity of participants was not reported.
} 
other studies have shown that the emotion people feel in the present in response to a situation (e.g., a risky situation) influences their decision making and their associated evaluations (Bechara \& Damasio, 2005; Loewenstein, Weber, Hsee \& Welch, 2001). In line with Caruso's suggested explanation of TVA, there is evidence that people experience greater affect when thinking about the future compared to the affect they experience when thinking about the past, and that this is true for both positively and negatively valenced events (Caruso, 2010; Caruso et al., 2008; D’Argembeau \& Van der Linden, 2004; Rasmussen \& Berntsen, 2013; Van Boven \& Ashworth, 2007). This difference in the level of emotion people report when thinking about past versus future events will be referred to as temporal emotion asymmetry (TEA).

Caruso et al. (2008) describe some findings that support the suggestion that TEA can explain TVA. In their study (Study 2c), participants who imagined helping their neighbor move house in the future felt they should get a significantly more expensive bottle of wine as a thank-you gift than those who imagined having already helped their neighbor in the past. Participants imagining the event in the future also experienced significantly greater negative affect when imagining carrying out the work and, crucially for Caruso's hypothesis, this negative affect mediated the effect of temporal location on participants' valuations. On this hypothesis, TEA can be seen as the more basic asymmetry that can potentially explain other asymmetries. Additional evidence for this claim comes from research that has demonstrated temporal asymmetries in moral judgment: Future transgressions are judged to be more deliberate, less moral, and more worthy of punishment than equivalent transgressions in the past (Burns, Caruso, \& Bartels, 2012; Caouette et al., 2012; Caruso, 2010). Caruso (2010) found that this can at least in part be explained by the stronger affect that thinking about future transgressions elicits compared to thinking about those in the past. 
Caruso's argument also extends to trying to explain why TEA itself, as the more fundamental asymmetry, exists. He suggests that this is due to basic differences between the past and future: because the future is by definition more controllable but also more uncertain than the past, thinking about future events elicits stronger emotions (see also Caouette et al., 2012). Such a claim is in line with other research that indicates that controllability and uncertainty are important factors in determining one's emotion response when considering certain events (e.g., Bar-Anan, Wilson, \& Gilbert, 2009; Vosgerau, Wertenbroch, \& Carmon, 2006; Wilson, Centerbar, Kermer, \& Gilbert, 2005). Suhler and Callender (2012) make a related line of argument, suggesting that lack of knowledge about the future means that people inevitably rely more on simulation when thinking about what is yet to come than when remembering the past, and that this can systematically lead to overestimations of the affective impact of events in the future. This is because such simulations are typically based primarily on focal aspects of events to the neglect of more peripheral event features or aspects of the event context that might moderate affective impact: for example, in simulating a future holiday, one might imagine relaxing days in the sun but fail to consider the possible effects of the beach being very crowded (Morewedge, Gilbert, \& Wilson, 2005; Wilson \& Gilbert, 2003). Along with Caruso, they suggest that TVA stems from the resultant TEA; moreover, they suggest that TEA makes evolutionary sense because stronger affect directed toward the future is of adaptive value insofar as it focuses resources on preparing for what is to come.

A tendency to be more concerned with the future than the past may also manifest in the way that (at least Western) adults map time onto space (Caruso, Van Boven, Chin, \& Ward, 2013; see also de la Fuente, Santiago, Román, Dumitrache \& Casasanto, 2014). These authors argue that people represent themselves as moving toward a future that is in front of them and away from the past, and as a result of this " $[\mathrm{J}]$ ust as approaching objects in physical 
space seem closer than receding objects, approaching points in time may seem psychologically closer than receding points in time" (Caruso et al., 2013, p. 531). Indeed, people tend to report that events in the future feel subjectively closer in time than events an equivalent distance in the past (we will label this temporal distance asymmetry, or TDA). For example, if asked to give ratings of how close Valentine's Day feels in time, participants will judge it to feel closer a week before the event than a week after the event. Furthermore, Caruso et al.'s study provides some support for their specific explanation of this in terms of spatial representation of time: they demonstrated that TDA could be abolished if the direction that participants perceived themselves to be moving in space was reversed in a virtual environment. Notably, Caruso et al. also suggest that TDA may itself at least partially explain TEA, stating that "We suspect that one reason people are more emotionally oriented to the future is that the future is psychologically closer than the past." (p. 535).

In summary, a number of temporal asymmetries have been reported in adults' judgments about the past versus the future, and there are some suggestions as to the nature of the psychological processes that may underpin such asymmetries. Such suggestions emphasize close links between the three types of asymmetries we have discussed here, to the extent that one type of asymmetry (either TEA or TDA) might be conceptualized as a more primary type of asymmetry that underpins or explains the others. However, research on temporal asymmetries is relatively recent and broadly aimed at demonstrating these effects rather than delineating between and testing competing accounts of them.

\section{Temporal Asymmetries and Development}

If an evolutionary explanation of TVA and TEA is correct, then we might expect such asymmetries to be universal and perhaps emerge early in development. However, one crosscultural study found that a sample of Chinese adults showed a reverse TVA, in that this group of adults valued past experiences more than future ones (Guo et al., 2012). These cross- 
cultural findings are notable because they may help shed light on the mechanisms underpinning TVA. Indeed, Guo et al. proposed that TVA occurs because people have a tendency to focus on a particular time (i.e., the past, the present, or the future) and as such they have a predominant temporal orientation. Crucially, this orientation may vary across cultures. Guo et al. use the term temporal orientation to capture people's tendency to spend more time thinking about, focus more extensively on, and draw more on information from a particular temporal location, a tendency assumed to influence people's behaviors, attitudes and actions (for closely related notions, see Briley, 2009; Holman \& Silver, 1998; Shipp, Edwards \& Lambert, 2009; Zimbardo \& Boyd, 1999). Guo et al. suggested that the asymmetries in valuations they observed can be explained by assuming that North Americans are future-oriented and Chinese participants are past-oriented. The view that cultural differences in temporal orientation may, at least in part, explain cultural differences in TVA gains some plausibility from the findings of studies that have observed differences between groups of individuals in their temporal orientation and consequently their attitudes and behaviors (Ashkanasy, Gupta, Mayfield, \& Trevor-Roberts, 2004; Sircova et al., 2014; Sircova et al., 2015). However, as yet Guo et al.'s study is the only one to have examined cross-cultural differences in TVA, and it is not yet clear how robust such differences are or whether it is useful to explain these dissimilarities in terms of temporal orientation.

Although Suhler and Callender (2012; see also Callender, 2017) suggest that temporal asymmetries may have evolved because of their adaptive value, it is possible that the temporal asymmetries observed in Western adults may themselves have emerged at some point in development, perhaps as a consequence of acquiring a temporal orientation that is future-focused. Indeed, as mentioned above, a recurring idea in the developmental literature on decision making is that children and adolescents may not be as future-oriented as adults (e.g., Greene, 1986; Nurmi, 1991; Steinberg et al., 2009), and as a result may make poorer 
quality decisions. A variety of questionnaire-based, interview, and self-report studies using disparate methodologies suggest that there are increases from late childhood across adolescence in the extent to which individuals anticipate and weigh the future consequences of their actions and well as engage in long-term planning (e.g., Cauffman \& Steinberg, 2000; Chen \& Vazsonyi, 2011; Grisso et al., 2003; Lewis, 1981; Nurmi, 1991; Steinberg et al.). Another line of empirical work that one could take as providing evidence for the idea that there are developmental changes in future-orientation is the body of research on temporal discounting. Developmental studies have typically shown age-related changes in the extent to which the future is discounted and the steepness of discounting function (e.g., Green, Fry, \& Myerson, 1994; Prencipe et al., 2011; Steinberg et al., 2009), with development continuing across adolescence. Indeed, Steinberg et al. showed that developmental differences in temporal discounting were (at least partially) mediated by age differences in self-reported future-orientation.

These studies suggest that there are developmental changes in a tendency to be primarily concerned with the here-and-now, but in themselves do not inform us about whether there are also developmental changes in past-future asymmetries. One strand of research has emphasized the similarity of developmental changes in past and future thinking: it has been suggested that the ability to episodically remember the past and imagine the future (episodic future thinking; Atance \& O’Neil, 2001) develop in tandem, in line with claims that these abilities draw on a single system (Buckner \& Carroll, 2007; Suddendorf \& Corballis, 2007). By the time children are around four years, they can produce (albeit often basic) descriptions of specific past and future events; moreover, episodic past and future thinking skills are correlated in children of all ages (Coughlin, Lyons, \& Ghetti, 2014; Gott \& Lah, 2014; Hayne, Gross, McNamee, Fitzgibbon, \& Tustin, 2011; Suddendorf \& Busby, 2005). Both types of episodic thinking develop substantially during the preschool period and 
continue to improve across middle childhood into adolescence (Abram, Picard, Navarro, \& Piolino, 2014; Coughlin et al., 2014; Coughlin, Robins, \& Ghetti, 2017; Hayne et al.; Gott \& Lah, 2014; Wang, Capous, Koh, \& Hou, 2014).

However, although there is evidence that episodic past and future thinking develop in tandem, there is also some evidence to suggest that episodic future thinking develops more slowly that episodic memory (Coughlin et al., 2014; Gott \& Lah, 2014) and this appears to be true cross-culturally (Wang et al., 2014). Young children also find it more difficult to reason about future events compared to past events (Friedman, 2003; McColgan \& McCormack, 2008; McCormack \& Hanley, 2011). This might have implications for whether children show the same range of temporal asymmetries as seen in adults: if children have particular difficulties with thinking about the future, this potentially might mean that they do not show the same types of cognitive biases regarding the future as adults. However, little is known about how episodic thinking skills per se contribute to these asymmetries.

Thus, there are some converging lines of evidence that suggest that temporal asymmetries might emerge developmentally. Alternatively, if such asymmetries reflect a hard-wired tendency for motivational and emotional states to be future-directed, it may be that temporal asymmetries are observable as early as it is possible to measure them. The current studies are the first attempt that we are aware of to examine the developmental profile of temporal asymmetries. In addition to providing novel insights into how thought about the past and future changes developmentally, studying temporal asymmetries in a developmental context is valuable because it may clarify the nature of the asymmetries themselves. In particular, such studies allow us to examine in more detail the relations between the different asymmetries. As discussed, two specific claims have been made about these relations. First, Caruso et al. (2008) argued that TEA is the more basic asymmetry that may explain TVA. If this is correct, then TVA should not occur earlier in development than TEA. More recently, 
Caruso et al. (2013) have suggested that TDA may itself at least in part explain TEA (and perhaps in turn TVA), making it interesting to examine the developmental relation between these asymmetries. The more general point is that, in adult samples, these temporal asymmetries co-occur and thus have been interpreted as a coherent set of effects, perhaps underpinned by a single factor (such as temporal orientation), but we do not know if they cooccur in children. It could be that the asymmetries show different developmental profiles, or their relations to each other may change developmentally. That in itself would have implication for how we understand these effects.

\section{Overview of Studies}

In each of the studies reported here children were asked to think about real events, as opposed to hypothetical events, and were asked to make emotional, value, and subjective distance judgments in response to those events. The experimental variable of interest was the temporal location of the event (near future versus equidistant past). Across all studies, the events that we used were conventional holidays: Christmas, Easter, and Halloween. We used holidays because it was necessary to find specific real-life events that all participants across a wide range of ages would be encountering, and we were confident that even the youngest participants (4- to 5-year-olds in Study 3) would be aware of these holidays. In Study 1 children aged 6-to-7 and 9-to-10, adolescents aged 14-to-15, and undergraduates were asked about their Easter break from school/university, either 2 weeks prior to or 2 weeks after their break. Pilot work had previously indicated that emotion judgments of children tend towards ceiling. To mitigate this, we first presented 6-7-year-olds and 9-10-year-olds with an emotion scale training exercise: children were given pictures of 5 events, carefully selected to vary in emotional intensity and valence, and were asked to order them along the emotion scale according to how they would feel if the event happened to them. 
Following the established procedure in the literature the value judgments of adults were elicited using monetary scales. Given their young age we considered a monetary value scale unsuitable for the two child groups. Instead we developed a value scale based on homework sheets; children had to judge how many extra homework sheets they would be prepared to complete to extend their break. Though they were not pre-trained on the use of this scale, the children included in this study usually received their homework on individual sheets, typically one sheet per subject (e.g., one sheet for math, one for English), so they were very familiar with the idea of completing a certain number of homework sheets.

\section{Study 1: Easter Break}

\section{Method}

Participants. A total of 491 participants across four age groups were recruited for this study: one hundred and twenty-three 6 -to-7-year-olds $\left(M_{\mathrm{age}}=7\right.$ years 3 months $(7 ; 3)$, range $=$ $6 ; 8-7 ; 10), 61$ of whom were female; one hundred and six 9-to-10-year-olds $\left(M_{\text {age }}=10 ; 3\right.$, range $=9 ; 9-10 ; 9), 54$ of whom were female; 81 adolescents $\left(M_{\text {age }}=14 ; 11\right.$, range $=14 ; 3-$ 15;9), 32 of whom were female and 172 adults $\left(M_{\text {age }}=21\right.$ years, range $\left.=18-38\right), 118$ of whom were female. Written parental consent was obtained for all child and adolescent participants whereas adult participants provided written consent themselves. Child and adolescent participants were recruited from local schools whereas adult participants were psychology undergraduates recruited through lab classes. All participants took part in a single testing session, lasting approximately 5-10 minutes. Participants were assigned to the past ( $n$ $=212)$ or future condition $(n=279)$ according to their school and classroom (children and adolescents) or lab class (adults). Within participating schools, classes were randomly assigned to each condition. Ethical approval for this study and each subsequent study was received from the research ethics committee of the lead author's institution. 
Materials. Participants in all age groups reported their emotions using a 7-point emotional faces scale $(0=$ very sad; $3=$ not sad, not happy, just normal; $6=$ very happy $)$ (reproductions of all the scales used in these studies can be found in the supplemental material). Valuations and subjective distance ratings were obtained using 10-point Likert scales specially developed for this study, based on previous pilot work developing ageappropriate scales. For the two youngest age groups each point on the value scale consisted of a sample homework sheet(s), below which an integer indicated a total number of homework sheets (starting at 1 and increasing by 1 until point 6 , then $10,14,17$, and 20 ). For the adolescent group each point on the valuation scale was a gift box with a price listed below. The value of the gift varied from $£ 10$ to $£ 200$, rising (as did the size of the gift box). For the adults, the value scale depicted cash amounts starting at $£ 10$ and like the adolescent value scale rising to $£ 200$. For the purposes of analysis all valuations were converted onto a 10 point scale ranging from 0 to 9 . For 2 youngest age groups each point on the subjective distance scale was represented by a weekly calendar of decreasing size as one moved from really soon (scored as 0 ) to really long time away (scored as 9). The distance scale for both adolescents and adults was a straight 10-point line, with ends labelled 'really short time ago / really short time from now' and 'really long time ago / really long time from now'.

Procedure. Participants were tested in groups either two weeks prior to or two weeks after their Easter break. Testing took place in groups for these and the other studies because of the need to collect data from a very large sample of participants within a short window of time (two weeks before and two weeks after the events in question). The testing session for the two youngest age groups began with a training exercise for the emotion scale. The emotion scale was introduced and each point was explained in turn. Each child ordered 5 different events selected to elicit emotion of varying valence and strength (e.g., 'riding a bicycle', 'losing a game' etc.) on the emotion scale (in practice this involved placing pictures 
depicting each event on a Velcro strip running below the emotion scale). This was to encourage children to use points on the scale other than the end points; within any given testing group individual children were given different sets of events to place on the scale in order to encourage them to make subjective evaluations. All participants were then reminded that their Easter break from school/university would be happening (or had happened) in two weeks' time (or two weeks previous) and were asked to think about it briefly. Emotion ratings were elicited first: "When you think about what your Easter break will be like (was like), how does it make you feel right now?" Participants responded by circling one of the faces on the scale. Children were then told "I want you to imagine that you could have (had) three extra days off school for your Easter break. Imagine that to get these three extra days off school, you would have (had) to complete some extra homework sheets for your teacher. How many homework sheets would you be (have been) happy to do if it meant you could have (had) these three extra days off school for your Easter break?" Children responded by circling one of the numbers on the homework sheet scale. Adolescents were asked to imagine giving a gift to their teacher in order to receive three extra days off school without any effect on their assignments and then to indicate the value of the gift they would be willing to buy (would have bought). Undergraduates had to indicate how much cash they would pay (would have paid) if it meant they could have the three extra days off without any effect on their assignments. Lastly all participants were asked to indicate how far away their Easter break felt: "When you think about what your Easter break will be like in two weeks' time (was like two weeks ago), how far away does it feel? Does it feel like it will happen really soon (happened a really short time ago) or does it feel like it will happen in a really long time (happened a really long time ago)?"

\section{Results}


Analyses initially proceeded with a series of two way independent analyses of variance (ANOVA) examining the effect of temporal location and age group on each of the dependent measures. This was followed, where appropriate, with t-tests. For each dependent variable we took the mean difference between future and past condition and Cohen's $d$ as an unstandardized and standardized measure of the effect size, respectively. We also calculated the Bayes factors $\left(B F_{10}\right)$ as a measure of the strength of evidence in favor of the experimental hypotheses ${ }^{2}$. Means and standard deviations for all dependent measures are presented in the supplemental materials.

The mean emotion, valuation, and distance ratings across age groups and temporal conditions are displayed in Figures 1a, 1b, and 1c, respectively ${ }^{3}$. Standardized and unstandardized effect sizes, along with 95\% confidence intervals are displayed in Table 1 as are Bayes factors in favor of the experimental hypothesis. A two way ANOVA on emotion ratings with age group (four levels) and temporal location (two levels) as independent variables revealed a significant main effect of temporal location, $F(1,482)=33.08, p<.01$, $\eta^{2}=.06$. The main effect of age group was not significant, $F(3,482)=2.59, p=.05, \eta^{2}=.02$ and the interaction between temporal location and age group was non-significant, $F(3,482)=$ $0.33, p=.81, \eta^{2}=.002$. Independent sample t-tests revealed that emotion ratings in the future condition were significantly higher than the past condition for the 6-to-7-year-olds, $t(121)=$ $2.7, p<.01,9$-to-10-year-olds, $t(104)=2.4, p=.02$, adolescents, $t(79)=3.21, p<.01$ and adults, $t(178)=3.3, p<.01$.

Due to the different scales used in assessing value judgments (homework sheets, gift boxes and cash) analyses of adolescent and adult value judgments were conducted separately from that of children. A two way ANOVA on children's valuations revealed no main effect of either temporal location, $F(1,225)=2.53, p=.11, \eta^{2}=.01$, or age group, $F(1,225)=2.98$,

\footnotetext{
${ }^{2}$ Bayes factors greater than 1 favor the experimental hypothesis over the null hypothesis.

${ }^{3}$ Figures displaying standardized scores are presented in the supplemental materials.
} 
$p=.09, \eta^{2}=.09$. The interaction between age group and temporal location was also nonsignificant, $F(1,225)=0.52, p=.47, \eta^{2}<.01$. There was no significant effect of temporal location on value judgments of adolescents, $t(79)=-1.56, p=.12$. Surprisingly, adults' value judgments were higher in the past condition than in the future condition, $t(178)=-2.11, p=$ .04 .

Finally, a two-way ANOVA of distance ratings revealed a significant main effect of temporal location only, $F(1,481)=100.94, p<.01, \eta^{2}=.17$. Independent samples t-tests indicated that all four age groups judged the future event to feel closer in time than the past event: 6-to-7-year-olds, $t(121)=-4.54, p<.01,9$-to-10-year-olds, $t(103)=-4.45, p<.01$, adolescents, $t(79)=-5.96, p<.01$ and adults, $t(178)=-6.1, p<.01$. Correlational analysis revealed a weak negative relationship between emotion and distance judgments for the 6-to7-year-olds, $r=-.21,95 \% \mathrm{CI}[-.37,-.03], p=.02$. None of the other correlations were significant. Multiple regression analyses were conducted to assess the proposed mediating effect of subjective distance on the relationship between temporal location and emotion for the 6-to-7-year-old group. Distance judgments were unrelated to emotion judgments $(B=-$ $.06, t(120)=-1.46, p=.15)$, therefore the criteria for mediation analysis were not met (Baron \& Kenny, 1986).

\section{Discussion}

There was a clear effect of TEA and TDA for all four age groups. By contrast there was no effect of TVA in the predicted direction for any of the four age groups: indeed the reverse effect was found in the adult group, where the future event was valued less than the past event. The lack of interaction between age group and temporal location for emotion judgments indicates a similar sized effect of temporal location across all age groups. Inspection of the effect sizes and confidence intervals (Table 1) indicates a medium sized effect. From the evidence presented in this study, TEA is present from at least 6-to-7-years of 
age and does not change in size across development. The pattern that emerged with regard to emotion judgments was replicated with distance judgments. Participants of all ages judged the future event to be closer than the equidistant past event. An ANOVA revealed no interaction between temporal location and age group. The effect size was large for all four age groups (Cohen's $d>.8$ for each) suggesting that TDA is a robust phenomenon present from at least 6-to-7-years of age. The Bayes factors in favor of the experimental hypothesis were particularly large (all $B F_{10}>800$ ) indicating very strong evidence for the TDA effect. Despite a consistent effect of TDA and TEA across the entire sample, the correlations between emotion and distance judgments were non-significant for all bar the youngest group of participants. An account that attempts to reduce TEA to TDA (Caruso et al., 2013) gains little support from this data. The issue of the relation between the various asymmetries will be discussed further in the General Discussion.

Surprisingly, given the consistent effect of temporal location on emotion and distance judgments, we found no evidence that participants of any age valued the future event more than the past. This pattern is at odds with adult studies that have consistently found value judgments for future events to exceed the same judgments for past events (Caruso, 2010; Caruso et al., 2008; Guo et al., 2012; Roh \& Schuldt, 2014). Indeed, Caruso et al. reported both heightened emotion responses and increased value judgments for the same event (helping a neighbor move apartment) and found that the effect of temporal location on value judgments was fully mediated by the emotion asymmetry. Furthermore, using an event very similar to the present study, undergraduates were willing to pay $24 \%$ more to extend their future winter break for three extra days and rated their prospective enjoyment significantly higher than their retrospective enjoyment. Rather than replicating this effect the reverse value asymmetry was evident in our undergraduate sample, with three additional days of holiday valued less in the future than in the past. We believe that this reversed temporal asymmetry 
may in part be explained by the context of our target event. The Easter break preceded the student exam period and although we qualified the value question with the proviso that students could have the additional time off "without any effect on your assignments", we nevertheless suspect that the upcoming exam period may have influenced responses. Moreover, we speculate that this influence may have been asymmetric in the case of undergraduates. To begin with mean evaluations were very low. The mean valuation for undergraduates was just $£ 24$ (approximately $\$ 34$ at the exchange rate of the time ${ }^{4}$ ) on the scale going from $£ 10$ to $£ 200$. For adolescents it was even lower at $£ 19$ (\$27). Overall, $51 \%$ of the undergraduates and $58 \%$ of adolescents were at the lowest point of the valuation scale (£10). This was despite both age groups feeling relatively happy about their Easter break (mean emotion rating of 4.7 out of 6 for the undergraduates and 4.9 for the adolescents). Anecdotal evidence from debriefing indicates that many students in the future condition planned to spend their Easter break studying rather than at leisure. It may be that additional time off is less appealing when a period of intensive study is approaching than when looking back in retrospect at the end of a study period. Or it may be that additional time off on the eve of an intensive exam period is more appealing than when that exam period is a month and a half away.

In summary, Study 1 presents clear evidence of temporal asymmetries in judgments of emotion and subjective distance in children from 6-to-7-years of age. The predicted temporal asymmetry in value judgments was not in evidence at any age. In Study 2 we sought to replicate the effects of TEA and TDA with a new target event: the Christmas holiday period. We also revisited the issue of TVA. Although there was no effect of tense on 9-to-10year-olds value judgments, it may be that we lacked sufficient power to detect TVA (cf. Cohen's $d$ for the Caruso et al. 2008, Study 4 was 0.17). Indeed, the Bayes factor for TVA in

\footnotetext{
${ }^{4}$ By contrast the mean valuations in Caruso et al. Study 5 were $\$ 113.30$ for the future condition and $\$ 91.09$ for the past condition.
} 
the 9-to-10-year-olds was 1.02 indicating the test lacked sensitivity to distinguish between null and experimental hypotheses. In Study 2 a we examined emotion, distance, and value asymmetries in a sample of 6-to-7-year-olds and 9-to-10-year-olds. The choice of the Christmas holiday for the target event also allowed us to address the concern that post-Easter exams contributed to the lack of the predicted TVA in adolescents and adults. In Study $2 \mathrm{~b}$ we examined TVA in an adolescent sample for whom January was a period with few or no exams.

\section{Study 2a: Christmas Holidays}

\section{Method}

Participants. A total of 234 children across two age groups were recruited for this study: one hundred and sixteen 6-to-7-year-olds $\left(M_{\text {age }}=7 ; 0\right.$, range $\left.=6 ; 7-7 ; 6\right), 61$ of whom were female and 118 9-to-10-year-olds $\left(M_{\text {age }}=10 ; 0\right.$, range $\left.=9 ; 3-10 ; 8\right), 57$ of whom were female. Participants with parental consent took part in a single testing session, lasting approximately 5-10 minutes, alongside their participating classmates. Participants were assigned to the past or future condition according to their school and classroom: within participating schools, classes were randomly assigned to each condition. Sixty-nine 6-to-7year-olds and forty-nine 9-to-10-year-olds participated in the past condition. The responses of two 6-to-7-year-olds to the emotion question were uninterpretable due to their circling more than one option. Only their value and distance judgments were included in the analyses.

Materials. Children made emotion, value, and distance judgments using the same scales employed with the youngest two age groups in Study 1.

Procedure. Children were tested either two weeks prior to or two weeks after their Christmas holidays. As with Study 1, testing sessions began with a training procedure for the emotion scale. Children were then reminded that their Christmas holidays would be happening (or had happened) in two weeks' time (two weeks previous) and were asked to 
think about it briefly. The emotion question was asked first: "When you think about what your Christmas break was like (will be like) how does it make you feel right now?" To obtain value judgments, children were asked to imagine that they could get three extra days off school on return for doing extra homework sheets and to answer the following question: "How many homework sheets would you have done (would you do) if it meant you could have these three extra days off school for your Christmas break?". Finally, for the distance evaluation they were asked "When you think about what your Christmas break was like two weeks ago (will be like in two weeks' time), how far away does it feel? Does it feel like it happened a really short time ago (it will happen really soon) or does it feel like it happened a really long time ago (it will happen in a really long time)?"

\section{Results and Discussion}

The mean emotion, valuation, and distance ratings across age groups and conditions are displayed in Figures 2a, 2b, and 2c, respectively. Effect sizes, confidence intervals and Bayes factors are displayed in Table 2. A two way ANOVA revealed a main effect of temporal location emotion ratings, $F(1,228)=11.49, p<.01, \eta^{2}=.05$. There was no main effect of age group, $F(1,228)=0.76, p=.39, \eta^{2}<.01$ and no interaction between age group and temporal location, $F(1,228)=0.76, p=.39, \eta^{2}<.01$. As Table 2 reveals, emotion ratings were significantly higher in the future condition than in the past condition for both 6-to-7year-olds, $t(112)=2.6, p=.01$, and 9-to-10-year-olds, $t(116)=2.15, p=.03$. With regard to valuations a two way ANOVA revealed a main effect of age group only, $F(1,228)=18.06, p$ $<.01, \eta^{2}=.07$. There was no effect of temporal location, $F(1,230)=2.71, p=.1, \eta^{2}=.01$ and no interaction between temporal location and age group, $F(1,230)=1.97, p=.16, \eta^{2}=.01$. Six-to-seven-year-olds valuations were significantly higher than 9-to-10-year-olds, $M D=$ $1.73,95 \%$ CI $[0.88,2.59]$. Finally, a two way ANOVA on distance judgments revealed a main effect of temporal location only, $F(1,230)=60.41, p<.01, \eta^{2}=.21$. The future event 
felt closer to the present than did the past event for both 6-to-7-year-olds, $t(114)=-5.2, p<$ .01 and 9-to-10-year-olds, $t(116)=-5.92, p<.01$.

Correlational analysis revealed a significant negative correlation between emotion judgments and distance judgments for both age groups. For the 6-to-7-year-olds the Pearson correlation was $r=-.28,95 \%$ CI [-.44, -.10], $p=.01$, indicating that greater distance judgments were associated with reduced emotion ratings. The association between emotion and distance was similar for the 9-to-10-year-olds, $r=-.19,95 \%$ CI $[-.35,-.01], p=.04$. Multiple regression analyses were conducted to test the proposed mediating effect of distance judgments on the relation between temporal location (past versus future) and emotion. Temporal location was associated with emotion ratings $(\mathrm{B}=0.65, t(230)=3.6, p<.01)$ and distance judgments $(\mathrm{B}=-2.92, t(230)=-7.68, p<.01)$. There was a negative link between distance judgments and emotion judgments $(\mathrm{B}=-0.11, t(230)=-3.83, p<.01)$. As both the proposed $\mathrm{a}$ and $\mathrm{b}$ paths were significant, mediation analysis was conducted using the bootstrapping method (5000 bootstrapping resamples) with bias corrected $95 \%$ confidence intervals (Preacher \& Hayes, 2008). Results confirm a mediating role for distance judgments on the relationship between temporal location and emotion $(\mathrm{B}=0.23,95 \% \mathrm{CI}[0.03,0.45])$. However, this was just a partial mediation as the direct effect of temporal location on emotion remained significant $(\mathrm{B}=0.42, t(230)=2.11, p=.04)$.

Study 2 a replicates the TEA and TDA effect found in Study 1 and strengthens our conclusion that these effects are present from at least 6-to-7-years of age. Cohen's $d$ for the TEA was similar in size across both age groups and both studies (a medium size effect ranging from 0.4 to 0.5 ). Likewise, Cohen's $d$ for the TDA effect was consistently large in size across both age groups and both studies (ranging from 0.82 to 1.11 ). With respect to children's valuations, Study 2a again indicated no effect of temporal location. However, inspection of the TVA effect sizes and confidence intervals (Table 2) suggest a slightly 
different picture: 9-to-10-year-olds future valuations are significantly higher than their past valuations $(M D=1.33,95 \%$ CI $[0.29,2.38])$. Likewise, the Bayes factor was 3.32 indicating moderate support for the experimental hypothesis over the null hypothesis. Although Study 1 also found no significant difference between past and future valuations we note that the confidence intervals around the TVA effect size for 9-to-10-year-olds in both studies substantially overlap. Study 1 and Study 2a used identical procedures, the only difference being the target event. We conducted a two way independent ANOVA on 9-to-10-year-olds value judgments with temporal location (past versus future) and study (1 versus 2 ) as factors. There was a significant main effect of temporal location, $F(1,220)=9.97, p<.01, \eta^{2}=.04$, with the valuations in the future condition $(M=3.99)$ higher than in the past condition $(M=$ 2.85). There was no main effect of study, $F(1,220)=1.38, p=.24, \eta^{2}=.01$, and no interaction between temporal location and study, $F(1,220)=0.29, p=.59, \eta^{2}<.01$. The 6 to-7-year-olds by contrast showed no evidence of TVA in either Study 1 or Study 2a. Thus these two studies taken together suggest that TVA emerges developmentally sometime between 6-to-7-years and 9-to-10-years, later than the age at which TEA and TDA are established.

In both studies we examined the association between emotion, value, and distance judgments. Like Study 1, Study 2a found a negative association between distance judgments and emotion ratings for the youngest age group. Study 2 a revealed a weak negative association between distance and emotion judgments for the 9-to-10-year-olds. We tested a mediation model based on the suggestion of Caruso et al. (2013) that emotional asymmetry arises from the future feeling closer than the past. The results were inconclusive, in so far as the model indicated both a partial mediation and a residual direct effect of temporal location on emotion judgments. We will return to the issue of the relationship between these three effects in the General Discussion. 
In Study $2 b$ we examined temporal emotion, value, and distance asymmetry concerning the Christmas holidays in a sample of adolescents. We sought to confirm the developmental picture emerging from the first two studies, indicating that TEA and TDA are well established before adolescence and do not undergo any significant shift in magnitude. A second aim was to address the concern that the lack of TVA in Study 1 arose from the positioning of the Easter break prior to an intensive exam period. Whereas all the adolescent and undergraduate participants from Study 1 would have sat May exams, only a minority of adolescents in Study $2 \mathrm{~b}$ would have sat January exams.

\section{Study 2b: Christmas Holidays}

\section{Method}

Participants. A total of 662 adolescents (473 female) ranging from 14 to 18 years of age participated in this study $\left(M_{\mathrm{age}}=16 ; 1, S D=14\right.$ months). Those under 16 years of age provided written parental consent, while those aged 16 years and older gave written consent themselves. Participants took part in a single testing session, lasting approximately 5-10 minutes, alongside their participating classmates. Participants were assigned to the past or future condition according to their school and classroom: within participating schools, classes were randomly assigned to each condition. In total 361 participants were assigned to the past condition.

Materials. Adolescents made emotion, value, and distance judgments using the same scales employed with adolescents in Study 1.

Procedure. Participants were tested either two weeks prior to or two weeks after their Christmas holidays. They were first reminded that their Christmas holidays would be happening (or had happened) in two weeks' time (two weeks previous) and were asked to think about it briefly. Firstly, participants were asked: "When you think about what your Christmas break was like (will be like) how does it make you feel right now?" Next, in order 
to obtain subjective value judgments, participants were instructed to imagine that they could get three extra days off school by buying a gift for their teacher and asked: "How much would you be willing to spend on a gift for your teacher if it meant you could extend your Christmas break by three days without any disruption to your obligations, such as school assignments etc.?" Finally, participants estimated temporal distance with the following prompt: "Think about your Christmas break and complete the following sentence by circling one of the options (1-10). It feels like my Christmas break is...?"

\section{Results and Discussion}

The mean emotion, valuation, and distance ratings by condition are displayed in Figures $2 \mathrm{a}, 2 \mathrm{~b}$, and $2 \mathrm{c}$ respectively and the corresponding effect sizes, confidence intervals and Bayes factors are displayed in Table 2. An independent samples t-test revealed significantly higher emotion ratings in response to the future event, $t(660)=6.93, p<.01$. The future event was also valued more, $t(659)=4.54, p<.01$. And the future event felt closer to the present, $t(660)=-16.17, p<.01$.The Bayes factors for all three effects indicated extreme support for the experimental hypothesis over the null hypothesis (all $B F_{10}>1000$ ). Correlational analysis revealed a significant negative correlation between emotion and subjective distance, $r=-.18,95 \%$ CI [-.25, -.11], $p<.01$. Regression analysis indicated that there was no influence of distance on emotion when controlling for temporal location, therefore mediation analysis was not attempted.

Thus data collected from adolescents reveals the same pattern of past-future asymmetries observed in a sample of 9-to-10-year-olds: there is a medium size effect of temporal location on emotion ratings, a large effect of temporal location on distance judgments, and a small but significant effect of temporal location on value judgments (see Table 2). Furthermore, as with 6-to-7-year-olds in Study 1 and 2a and the 9-to-10-year-olds 
in Study 2a, there was a weak negative relationship between emotion and distance judgments, while value judgments were unrelated to either.

Although the results of Studies 1 (Easter) and 2 (Christmas) are consistent in demonstrating emotion and distance asymmetries, future events were valued more than past events by adolescents only in Study 2 . We have already suggested that this may have been due to the fact that adolescent and undergraduate participants had exams very soon after their Easter holidays, which may have meant they did not value additional days away from school/university at Easter, whereas this was not true for participants in Study 2. A further possibility is that the differences in the findings between the studies lie in the nature of the Christmas and Easter events themselves (e.g., Christmas is a more salient event that is enjoyed more than Easter). While we cannot rule out this possibility, we note that the distance judgments and the emotion judgments for both events are very similar despite being collected with different samples. Nevertheless, it is important to bear in mind that there may be a variety of differences regarding these events that could influence valuations. Our findings suggest that, although Caruso et al. (2008) found TVA across a variety of different hypothetical events, when examining TVA for real-life events, event choice may affect whether TVA is observed.

A further issue concerns the use of different scales for event valuation across Studies 2a and 2b: homework sheets for children and a monetary scale for the adolescents. In our judgment, it would be impossible to use the same value scale for such a wide age-range of participants, and thus we cannot directly compare the data across the two studies (although our findings demonstrate that use of similar emotion and temporal distance scales was appropriate). Thus, the important issue is whether the scales are each sufficiently sensitive to pick up temporal asymmetries within the relevant age range. We note that inspection of effect sizes (Table 2) shows that the TVA effect is in fact larger in the 9- to 10-year-olds than the 
adolescent group. Because of the use of different valuation scales, we would not want to interpret this as suggesting that TVA reduces in size with age; however, the data are consistent with our interpretation that, once established, temporal asymmetries do not increase in magnitude developmentally. Having established emotion asymmetry and distance asymmetry among 6-to-7-year-olds our final study sought to look for these asymmetries in an even younger age group: 4-to-5-year-olds. Given the lack of a value asymmetry among 6-to7-year-olds and the potential difficulty young children might have with recursive counterfactuals ("if you could have had three extra days of school, how much extra homework would you have been willing to do?") we decided not to elicit value judgments in this final study.

\section{Study 3: Halloween}

\section{Method}

Participants. A total of 281 four- and five-year-olds (140 female) participated in this study $\left(M_{\text {age }}=5 ; 4\right.$, range $\left.=4 ; 2-6 ; 2\right)$. One child's response to both dependent measures was uninterpretable due their circling more than one option. The response of a further 5 children to one or other measures was uninterpretable for the same reason and were not considered in the analysis. The final sample, therefore, consisted of 280 participants, 275 of whom provided full data. Participants with informed parental consent took part in a single testing session, lasting approximately 5-10 minutes, alongside their participating classmates. Participants were assigned to the past or future condition according to their school and classroom: within participating schools classes were randomly assigned to each condition. There were 158 participants in the future condition and 122 in the past condition.

Materials. The same 7-point emotional faces scale that was used in Studies 1 and 2 was employed in this study. A modified 10-point subjective distance scale was employed: it depicted a long straight path with a cartoon character stood at the beginning. In the future 
condition the character was looking along the path while in the past condition the back of the character was turned to the path. There were 10 red markings evenly spaced along the length of the path.

Procedure. Participants were tested either two weeks before or two weeks after their Halloween break. Testing took place in a quiet resource area of participating schools with groups of no more than 8 children at a time. Testing began with the same training procedure for the emotion scale training that had been used in Studies 1 and 2: each point on the emotion scale was described after which children were given five emotion vignettes and were encouraged to order them along the emotion scale according to how they would feel should each event happen to them. Children were then asked to think briefly about their Halloween break. Emotion ratings were elicited as follows: "When you think about what Halloween was like (will be like), how does it make you feel right now? Use your pencil to circle the face that shows how you feel".

A distance scale training procedure was introduced. Children were first asked to think about the near and distant past (past condition) or near and distant future (future condition). The distance scale was then presented to children and they were told that they would use it to show how far away some things are that have happened (will happen) to them. To assist children's calibration of the scale the experimenter placed three sample events at the scale's beginning and end. As Halloween falls exactly halfway between the start and end of the school term we used a picture of children arriving at school at the start of term to mark the end point of the scale in the past condition and children playing in snow during the Christmas holidays to mark the end point of the scale in the future condition (both events were approximately two months away). The beginning of the scale was marked by two events, eating breakfast that morning and going to bed the previous evening in the past condition and having dinner later that day and going to bed that same evening in the future condition. 
Children were then given their own copy of the distance scale, reminded about their Halloween holidays and asked "When you think about what Halloween was like (will be like), how far away does it feel? Use your pencil to circle the red bit on the picture that shows how far away it feels".

\section{Results}

The mean emotion and distance ratings by condition are displayed in Figures $3 \mathrm{a}$ and $3 \mathrm{~b}$, respectively and the corresponding effect sizes, confidence intervals and Bayes factors are displayed in Table 2. An independent samples $t$-test on emotion ratings was not significant, $t(275)=1.19, p=.06$. The future event felt closer to the present than did the past event, $t(276)=-3.11, p<.01$. A Pearson's correlation analysis of emotion and distance judgments was non-significant, $r=-.05,95 \%$ CI $[-.17, .07], p=.4$.

\section{Discussion}

There was a clear effect of TDA in the predicted direction, with children judging Halloween to be closer to the present in the future condition than in the past condition. Although the emotion ratings in the past condition were lower than in the future condition the mean difference was not significant. Moreover, the Bayes factor indicated that the data provide moderate support for the null hypothesis over the experimental hypothesis. The effect size of the TDA effect was smaller than in Studies 1 and 2, although interpretation of this is difficult given the changes in both scale and event. Our emotion scale training exercise was intended to encourage children to consider the entire range of the scale when making their emotion judgments. Nevertheless, $75 \%$ of participants rated themselves at the top point of the emotion scale (very happy). By contrast the comparable statistic for the 6-to-7-year-olds was $57 \%$ (Study 1) and 64\% (Study 2a). Given the lack of variance in children's use of the emotion scale it is perhaps unsurprising that emotion ratings failed to correlate with distance judgments. 


\section{General Discussion}

The studies reported here constitute the first attempt to examine temporal asymmetries of emotion, value, and distance in children and adolescents. In all of the age groups studied, including the youngest group, there was evidence of at least one temporal asymmetry in judgments. Moreover, asymmetries were generally similar in magnitude across a very wide age range. Together, these findings suggest that differences between past and future thinking are robust and emerge early in development. However, the three asymmetries we examined did not all emerge at the same age. First, TEA appears to be present in children from at least 6 years onwards, and once established the size of the TEA effect did not vary by age or scenario. Four-to-five-year-olds also reported somewhat greater happiness thinking about Halloween in the future than in the past, but the difference between these emotion judgments was not significant, perhaps because children of this age had a strong preference to use the end of the emotion scale meaning that there was little variability in judgments. Second, TDA appears to be present from at least 4-to-5-years of age. The magnitude of the TDA effect was small to medium sized in this youngest age group; however, from 6-to-7years of age onwards into adulthood the TDA effect was consistently large (all Cohen's $d>$ .8). Third, TVA is present in children from around age 9-to-10 years but there was no evidence of TVA in children aged 6-to-7 years. The TVA effect was the smallest and least consistent effect across 9-to-10-year-olds and adolescents.

\section{What Have We Learned About the Nature of Temporal Asymmetries?}

Our studies allowed to us to examine some previous claims about the relations between the asymmetries, namely Caruso et al.'s (2008) suggestion that TEA may underpin TVA and Caruso et al.'s (2013) hypothesis that TEA itself might be at least partially explained by TDA. Perhaps surprisingly, no support was found for the suggestion that people value the future more than the past because they feel more emotion when thinking about the 
future. Value judgments and emotion judgments were uncorrelated throughout. Furthermore, TVA appeared later in development than both TEA and TDA. On the issue of whether TDA may (at least partially) explain TEA, the evidence is more mixed. There were weak negative correlations between emotion and distance judgments for the youngest children in Study 1 and for the all three age groups in Studies $2 \mathrm{a}$ and $2 \mathrm{~b}$. However, mediation analysis proved inconclusive in attempting to specify the direction of causal influence between temporal location (past versus future) and the dependent variables, and distance judgments did not fully mediate the effect of temporal location on emotion judgments.

Although Caruso et al. (2013) suggested that stronger emotions regarding the future might stem from the future feeling closer than the past, our results suggest that TEA cannot be fully explained in this way, and instead merely replicate previous findings that emotion and distance judgments are (at least sometimes) related. Previous studies have established the existence of a correlation between emotion and distance judgments: for example, Ekman and Lundberg (1971) showed that within subjects there is a monotonic relation between emotional involvement and subjective distance ${ }^{5}$. What is less clear is the causal direction (if any) of such a relation. Notably, manipulations that vary the emotional intensity of both past and future events reduce the perceived psychological distance of those events (Van Boven, Kane, McGraw, \& Dale, 2010), suggesting that the causal direction is from emotion to distance. Moreover, a recent study of TDA with a sample of Chinese undergraduates (Gan, Miao, Zheng, \& Liu, 2016) reported that a priming manipulation that increased positive affect led to an increased TDA effect, though only in individuals who scored low in future orientation (Stratham, Gleicher, Boninger, \& Edwards, 1994). Evidence that the TDA may vary depending on the strength of emotions associated with the past and the future is provided by a study that found this effect was greatly reduced in participants with high levels

\footnotetext{
${ }^{5}$ The relationship was equally well described by a power function and an exponential function.
} 
of depression but enhanced in those with high anxiety (Rinaldi, Locati, Parolin, \& Girelli, 2016).

Although our data do not allow us to explain why distance and emotion judgments are correlated, the weakness of these correlations and the results of the mediation analysis, alongside the lack of correlations between either emotion or distance judgments and value judgments, makes it difficult to view any one asymmetry as primary. This, along with the fact that TVA does not appear to emerge at the same age as TEA or TDA, suggests that these asymmetries do not form a close coherent set. It remains plausible that these asymmetries share one or more common causal factors but any causal explanation would have to allow for the possibility that they do not always co-occur. We return to the issue below of how future developmental studies may help shed light on the factors underpinning temporal asymmetries.

\section{What Have We Learned About Development?}

One way of interpreting temporal asymmetries is as an index of future orientation, and indeed in the introduction we pointed to claims within the developmental literature that children and even adolescents may not be as future-oriented as adults. Do our results provide any support for such a suggestion? On the face of it there is little support in these data for such a view. Both TDA and TEA appeared early in development and once established at age 6-to-7 displayed no developmental change. The effect sizes for both were consistent across all ages bar the youngest sample in Study 3. It was only in response to value questions that there was evidence of developmental change. In contrast to older children and adults, 6-to-7year-olds showed no sign of valuing future events any more than past. If we see any evidence for the notion that children are not as future oriented as adults it is in a lack of TVA in this age group. 
At first sight one might be tempted to conclude that the pattern shown by 6-to-7-yearolds (evidence of TEA but not TVA) as indication that their value judgments are as yet unrelated to their emotions, the implication being that adult value judgments are closely related to affective states (Damasio, 1994). However, the lack of correlation between the value judgments and emotion judgments of older children, adolescents, and adults in the present study poses a problem for such a conclusion. Our findings suggest that, when thinking about temporally displaced events, present emotions are not necessarily a good guide to valuations ${ }^{6}$. A further possibility is that children of this age did not understand the value scale that they were asked to use. However, children's responses did not cluster at the ends of the scale and we are confident that the children were familiar with the idea of homework sheets used on the scale. Furthermore, children were able to use the emotion and distance scales competently, indicating that their difficulties were not with scale use per se. It remains possible, though, that children of this age found it problematic to make an entirely unfamiliar and hypothetical type of value assessment (i.e., judging the equivalence between amount of homework and notional extra days of holiday). Future studies could attempt to use different ways of asking children of this age to make value judgments.

Interpreting the pattern of age effects to indicate that the factors responsible for the future bias in valuations are not yet in place at age 6-to-7 raises the issue of what such factors might be. One difficulty in identifying these factors is that some of the candidates suggested in the extant temporal asymmetries literature (such as differences in certainty or extent of simulation) are primarily assumed to affect value judgments via their effect on emotions. One candidate factor which plausibly may have a more direct influence on valuations is temporal orientation. As mentioned above, Guo et al. (2012) found the TVA was reversed in Chinese

\footnotetext{
${ }^{6}$ It should be noted that the value questions in the present studies concerned a modified event (three extra days off school / university) to that presented in the emotion and distance questions. In contrast to this, Caruso et al. (2008) found that emotional responses mediated value judgments to the same event (e.g. 4 hours of tedious data entry). It is not obvious why the use of modified events should uncouple emotion and value judgments. Nevertheless, future developmental studies might explore this issue in more detail.
} 
adults, and they specifically linked this to cultural variation in temporal orientation viz. Chinese culture is more past-oriented whereas European North Americans are more futureoriented. Given the dissociations we have found between the different temporal asymmetries it may be that TVA relies on the emergence of a culturally mediated temporal focus, whereas TDA and TEA do not. We note that Gan et al. (2016) reported although the magnitude of the TDA effect in their sample of Chinese students was moderated by the extent to which participants were future-oriented, the direction of the effect (future closer than the past) was the same as in Western samples. This suggests that not only may the asymmetries not form a single coherent cluster when examined developmentally, they may also fail to do so crossculturally.

\section{Looking to the Future: How Developmental Studies May Shed Light on Temporal}

\section{Asymmetries}

As we have argued, the findings from this initial study of the development of temporal asymmetries have already been informative regarding the mechanisms underpinning such asymmetries, insofar as they have suggested that any explanation of these asymmetries must allow for the possibility of them dissociating developmentally. We suspect that future developmental studies of temporal asymmetries could be used to shed further light on the nature of these effects. One reason for this is that some claims about the mechanisms that result in temporal asymmetries imply that there may be certain cognitive pre-requisites that must be in place developmentally before the asymmetries can be observed.

First, as was mentioned in the introduction, Caruso et al. (2013) have argued that TDA emerges as a direct consequence of how time is mapped on to space (see also Rinaldi et al., 2016). If this is the correct explanation of this asymmetry, then our findings should be interpreted as suggesting that such temporal-spatial mapping is in place by at least 4-to-5 years of age. There has been a great deal of interest in whether children map time on to space, 
focusing primarily on whether children confound temporal duration and spatial magnitude (e.g., Casasanto, Fotakopoulou, \& Boroditsky, 2010; Piaget, 1969), but very little research has directly addressed whether children represent themselves as moving toward the future and away from the past. A recent study by Stites and Özçalışkan (2013) suggests that children understand the appropriate spatial metaphor in language from around age 5. Moreover, there is some preliminary evidence (Marghetis, Tillman, Srinivasan, \& Barner, 2014) that 8-yearolds' gestures map time on to space in the sagittal (forward to back) axis as well as the transversal left to right axis. However, although a number of studies with adults have demonstrated that they spontaneously evoke this type of spatial representation when thinking about the past and future (Koch, Glawe, \& Holt, 2011; Miles, Nind, \& Macrae, 2010; Sell, \& Kaschak, 2011), we do not know whether this is the case for children. Studying children's spontaneous mapping of time to space side-by-side with the development of TDA could prove very valuable in establishing whether time-space mapping underpins TDA.

Second, it has been argued that temporal asymmetries may be, at least in part, a consequence of the fact that the future is represented as being inherently uncertain (but more controllable) than the past (Caruso, 2010; Suhler \& Callender, 2012). Such a claim is compatible with, for example, the findings of studies with adults that have demonstrated that uncertain events are associated with greater emotion (Kurtz, Wilson, \& Gilbert, 2007; Wilson et al., 2005). If this is correct, then it raises the interesting developmental issue of whether understanding that the future is uncertain is a cognitive prerequisite for temporal asymmetries. Developmental studies that have examined children's understanding of the uncertainty of the future indicate that such an understanding may not fully develop until around 6 years (Beck, Robinson, Carroll \& Apperly, 2006; Lagattutta \& Sayfan, 2011), although more recently, on the basis of data from a simplified task, Redshaw and Suddendorf (2016) have suggested that such understanding may emerge some years earlier. Going 
forward it may prove useful to explore children's understanding of the ways in which the future differs from past alongside studying the development of temporal asymmetries in order to examine the role of the way the future is represented in explaining these effects.

Finally, there are a number of well-documented differences in past and future thinking (see Van Boven, Kane, \& McGraw, 2008 for a detailed list of these). Some of these differences are phenomenological ones (i.e., imagining the future is a different type of experience than remembering the past) and some are differences in the type of content that future simulations typically involve compared to memories of the past. As Van Boven et al. point out, many of these differences stem from the mundane but unavoidable fact that the past has happened and the future has not; as a result past tense mental simulation is inevitably more constrained by reality than future tense mental simulation. For example, in imagining a future event that has yet to obtain, people often rely on prototypical information about what usually happens in that type of situation and consider only salient aspects of the to-beimagined event at the expense of what may be important but less focal contextual details. What is as yet poorly understood is whether any of these differences in past and future thinking that have been documented are related to temporal asymmetries in judgments. Within a developmental context, it could prove fruitful to examine how any differences in the nature and content of past and future simulations relate to observed temporal asymmetries. As we pointed on in the introduction, there is some evidence that the ability to imagine future episodes develops more slowly that the ability to remember the past (Coughlin et al., 2014; Wang et al., 2014). However, if, as Van Boven et al. suggest, some temporal asymmetries are a result of the fact that future thinking relies more on prototypical information, the important developmental issue is not whether children find episodically imagining the future difficult, but whether they show the same tendency as adults to rely more on prototypical information in future than past simulation. Indeed, there is already some evidence that, by as young as 3-4 
years, there is more of a reliance on scripts about what usually happens when imagining the future compared to when remembering the past (Quon \& Atance, 2010), which suggests that this past-future difference in simulation could already be part of the explanation of the effects we see in young children.

\section{Future studies}

These initial studies of the development of temporal asymmetries raise a number of methodological issues that researchers conducting subsequent studies should consider, some of which we have already mentioned. One important issue concerns the choice of events used in the studies, which were all holidays. Although we had good reasons for using holidays (we wanted to use events that participants across wide age ranges would be encountering), it may be useful when focusing on a more limited age range to examine whether the effects we have found extend to other sorts of events. For example, if Van Boven et al. (2008) are correct that the greater use of prototypical information in future compared to past event simulation helps explain temporal asymmetries, then it might be useful to examine whether these effects can still can be observed for events for which children possess less prototypical information. Children are particularly likely to possess prototypical information about holidays (e.g., Christmas involves getting presents and special meals), so it might be useful to try to identify one-off novel events (e.g., a school trip to a place children have not visited before) for which participants possess limited prototypical information.

A second methodological issue concerns the use of between-subjects designs. We followed previous studies with adults in using separate groups for past and future judgments, given Caruso et al.'s (2008) findings that adults do not show temporal asymmetries in withinsubjects designs because they become aware of the inconsistency in their judgments. However, Caruso et al. asked participants to make past and future judgments in the same testing session (they were able to do so because they used hypothetical events); with the 
much longer gaps between testing session for real events it may be possible to use withinsubjects designs. A major advantage of such designs is that it would allow an examination of individual differences in temporal asymmetries, because each participant would make both past and future judgments (indeed, Rinaldi et al., 2017, successfully used a within-subjects design with adults to show that the magnitude of TDA was related to personality traits). Developmental studies could then examine, for example, how temporal asymmetries in children's judgments related to other aspects of cognition, such as time-space mapping, understanding of future uncertainty, or aspects of past and future thinking. Moreover, use of within-subjects designs would allow for the possibility of conducting longitudinal studies that may be particularly useful in shedding light on the developmental relations between the different asymmetries.

\section{Conclusions and Future Directions}

Asymmetries in judgments about the past and future can be observed relatively early in development, as might be predicted if it is assumed that biases towards the future in adults reflect basic adaptive features of human cognition. Our studies showed that three temporal asymmetries in past-future judgments that have previously only been studied in adults TDA, TEA, and TVA - are all present by at least 9-10 years, and do not increase in magnitude over adolescence. TVA is first observed by 9-10 years, and appears to be unrelated to both TEA and TDA. However, TDA and TEA emerge even earlier, from at least 4-to-5 years and 6-to-7 years respectively. In our studies, TDA was the largest and most robust asymmetry and furthermore it was in evidence developmentally as early as it is possible to measure it. Our findings suggest that the future typically really does feel closer than the past and that this reflects a fundamental characteristic of cognition that is intact early in development. 
Our interest in the development of temporal asymmetries stems from a broader interest in whether children become more future-biased over the course of development, and more specifically in whether age-related changes in decision-making might be linked to an emerging future bias. Our findings do not provide strong support for the idea that children are less future-biased than adults and instead suggest that temporal asymmetries may result from basic characteristics of cognition. In that sense, our results are at least compatible with Seligman, Railton, Baumeister, and Sripada's (2013) idea that the human cognitive system is primarily structured to focus on the future. However, we note that the notion of future bias is a broad one that has been operationalized in various ways in studies with adults, and measuring temporal asymmetries is only one way to approach this issue. In ongoing studies, we are exploring other ways of measuring whether there are developmental changes in future bias, such as examining whether the future plays as salient a role in children's mental lives by studying the temporal focus of mind-wandering. Examining the developmental origins of biases toward the future that are already known to exist in adults provides an important way of understanding how and why such biases arise. 


\section{References}

Abram, M., Picard, L., Navarro, B., \& Piolino, P. (2014). Mechanisms for remembering the past and imagining the future - New data from autobiographical memory tasks in a lifespan approach. Consciousness and Cognition, 29, 76-89. https://doi.org/10.1016/j.concog.2014.07.011

Addis, D. R., Wong, A. T., \& Schacter, D. L. (2007). Remembering the past and imagining the future: Common and distinct neural substrates during event construction and elaboration. Neuropsychologia, 45, 1363-1377.

http://dx.doi.org/10.1016/j.neuropsychologia.2006.10.016

Atance, C. M., \& O’Neil, D. K. (2001). Episodic future thinking. Trends in Cognitive Sciences, 5, 533-539. http://dx.doi.org/10.1016/S1364-6613(00)01804-0

Ashkanasy, N., Gupta, V., Mayfield, M. S., \& Trevor-Roberts, E. (2004). Future orientation. In R. J. House, P. J. Hanges, M. Javidan, P. W. Dorfman, \& V. Gupta (Eds.), Culture, leadership, and organizations: The GLOBE study of 62 societies (pp. 282-342). Thousand Oaks, CA: Sage.

Bechara, A., \& Damasio, A. R. (2005). The somatic marker hypothesis: A neural theory of economic decision. Games and Economic Behavior, 52, 336-372. http://dx.doi.org/10.1016/j.geb.2004.06.010

Baird, B., Smallwood, J., \& Schooler, J. W. (2011). Back to the future: Autobiographical planning and the functionality of mind-wandering. Consciousness and Cognition, 20, 1604-1611. https://doi.org/10.1016/j.concog.2011.08.007

Bar-Anan, Y., Wilson, T. D., \& Gilbert, D. T. (2009). The feeling of uncertainty intensifies affective reactions. Emotion, 9, 123-127. http://dx.doi.org/10.1037/a0014607

Baron, R. M. \& Kenny, D. A. (1986). The moderator-mediator variable distinction in social psychology research: Conceptual, strategic and statistical considerations. Journal of 
Personality and Social Psychology, 51, 1173-1182. http://dx.doi.org/10.1037/0022$\underline{3514.51 .6 .1173}$

Beck, S. R., Robinson, E. J., Carroll, D. J., \& Apperly, I. A. (2006). Children's thinking about counterfactuals and future hypotheticals as possibilities. Child Development, 77, 413-426. http://dx.doi.org/10.1111/j.1467-8624.2006.00879.x

Berntsen, D., \& Jacobsen, A. S. (2008). Involuntary (spontaneous) mental time travel into the past and future. Consciousness and Cognition, 17, 1093-1104. https://doi.org/10.1016/j.concog.2008.03.001

Boyer, P. (2008). Evolutionary economics of mental time travel? Trends in Cognitive Sciences, 12, 219-224. https://doi.org.10.1016/j.tics.2008.03.003

Briley, D. A. (2009). Looking forward, looking back: Cultural differences and similarities in time orientation. In E. R. S. Wyer, C. Y. Chiu, \& Y. Y. Hong (Eds.), Understanding culture: Theory, research and application (pp. 311-318). New York: Psychology Press.

Brink, D. O. (2011). Prospects for temporal neutrality. In C. Callender (Ed.), The Oxford handbook of philosophy of time (pp. 353-381). New York: Oxford University Press.

Buckner, R. L., \& Carroll, D. C. (2007). Self-projection and the brain. Trends in Cognitive Sciences, 11, 49-57. http://doi.org/10.1016/j.tics.2006.11.004

Burns, Z. C., Caruso, E. M., \& Bartels, D. M. (2012). Predicting premeditation: Future behavior is seen as more intentional than past behavior. Journal of Experimental Psychology: General, 141, 227-232. http://dx.doi.org/10.1037/a0024861

Busby Grant, J., \& Walsh, E. (2016). Exploring the use of experience sampling to assess episodic thought. Applied Cognitive Psychology, 30, 472-478. http://doi.org/10.1002/acp.3215

Callender, C. (2017). What makes time special? Oxford, England: Oxford University Press. 
Caouette, J., Wohl, J. A., \& Peetz, J. (2012). The future weighs heavier than the past: Collective guilt, perceived control and the influence of time. European Journal of Social Psychology, 42, 363-371. http://dx.doi.org/10.1002/ejsp.1857

Caruso, E. M. (2010). When the future feels worse than the past: A temporal inconsistency in moral judgment. Journal of Experimental Psychology: General, 139, 610-624. http://dx.doi.org/10.1037/a0020757

Caruso, E. M., Gilbert, D. T., \& Wilson, T. D. (2008). A wrinkle in time - Asymmetric valuation of past and future events. Psychological Science, 19, 796-801. http://dx.doi.org/10.1111/j.1467-9280.2008.02159.x

Caruso, E. M., Van Boven, L., Chin, M., \& Ward, A. (2013). The temporal Doppler effect: When the future feels closer than the past. Psychological Science, 24, 530-536. http://dx.doi.org/10.1177/0956797612458804

Casasanto, D., Fotakopoulou, O, \& Boroditsky, L. (2010). Space and time in the child's mind: Evidence for a cross-dimensional asymmetry. Cognitive Science, 34, 387-405. http://dx.doi.org/10.1111/j.1551-6709.2010.01094.x

Cauffman, E., \& Steinberg, L. (2000). (Im)maturity of judgment in adolescence: Why adolescents may be less culpable than adults. Behavioral Sciences and the Law, 18, 741-760. http://dx.doi.org/10.1002/bsl.416

Chen, P., \& Vazsonyi, A. T. (2011). Future orientation, impulsivity, and problem behaviors: A longitudinal moderation model. Developmental Psychology, 47, 1633-1645. http://dx.doi.org/10.1037/a0025327

Coughlin, C., Lyons, K. E., \& Ghetti, S. (2014). Remembering the past to envision the future in middle childhood: Developmental linkages between prospection and episodic memory. Cognitive Development, 30, 96-110. http://dx.doi.org/10.1016/j.cogdev.2014.02.001 
Coughlin, C., Robins, R. W., \& Ghetti, S. (2014). Development of Episodic Prospection: Factors underlying improvement in middle and late childhood. Child Development. $\underline{\text { http://dx.doi.org/10.1111/cdev.13001 }}$

Cumming, G. (2012). Understanding the new statistics. Hove, East Sussex: Routledge.

Damasio, A. R. (1994). Descartes' error. New York: Grosset/Putnam.

D’Argembeau, A., Renaud, O., \& Van der Linden, M. (2011). Frequency, characteristics and functions of future-oriented thought in everyday life. Applied Cognitive Psychology, 25, 96-103. http://doi.org/10.1002/acp.1647

D’Argembeau, A., \& Van der Linden, M. (2004). Phenomenal characteristics associated with projecting oneself back into the past and forward into the future: Influence of valence and temporal distance. Consciousness and Cognition, 13, 844-858. http://dx.doi.org/10.1016/j.concog.2004.07.007

de la Fuente, J., Santiago, J., Román, A., Dumitrache, C., \& Casasanto, D. (2014). When you think about it your past is in front of you: How culture shapes spatial conceptions of time. Psychological Science, 25, 1682-1690.

https://doi.org/10.1177/0956797614534695

Dougherty, T. (2011). On whether to prefer pain to pass. Ethics, 121, 521-537. https://doi.org/10.1086/658896

Dougherty, T. (2015). Future-bias and practical reason. Philosophers'Imprint, 15, 1-16. http://hdl.handle.net/2027/spo.3521354.0015.030

Ekman, G., \& Lundberg, U. (1971). Emotional reactions to past and future events as a function of temporal distance. Acta Psychologica, 35, 430-441. https://doi.org/10.1016/0001-6918(71)90002-3

Fraisse, P. (1963). The psychology of time. Oxford, England: Harper \& Row. 
Friedman, W. J. (2003). The development of a differentiated sense of the past and the future. Advances in Child Development and Behavior, 31, 229-269. https://doi.org/10.1016/S0065-2407(03)31006-7

Gan, Y., Miao, M., Zheng, L., \& Liu, H. (2016). Temporal Doppler effect and future orientation: Adaptive functions and moderating conditions. Journal of Personality, 85, 313-325. http://dx.doi.org/10.1111/jopy.12242

Gott, C., \& Lah, S. (2014). Episodic future thinking in children compared to adolescents. Child Neuroscience: A Journal on Normal and Abnormal Development in Childhood and Adolescence, 20, 625-640. http://dx.doi.org/10.1080/09297049.2013.840362

Green, L., Fry, A. F., \& Myerson, J. (1994). Discounting of delayed rewards: A life-span comparison. Psychological Science, 5, 33-36. http://dx.doi.org/10.1111/j.1467$\underline{9280.1994 . t b 00610 . x}$

Greene, A. (1986). Future-time perspective in adolescence: The present of things future revisited. Journal of Youth and Adolescence, 15, 99- 113. http://dx.doi.org/10.1007/BF02141732

Greene, P., \& Sullivan, M. (2015). Against time bias. Ethics, 125, 947-970. https://doi.org/10.1086/680910

Grisso, T., Steinberg, L., Woolard, J., Cauffman, E., Scott, E., Graham, S., Frances J., Lexcen, N., Reppucci, D., \& Schwartz, R. (2003). Juveniles’ competence to stand trial: a comparison of adolescents' and adults' capabilities as trial defendants. Law and Human Behavior, 27, 333-363. http://dx.doi.org/10.1023/A:1024065015717

Guo, T., Ji, L., Spina, R., \& Zhang, Z. (2012). Culture, temporal focus, and values of the past and the future. Personality and Social Psychology Bulletin, 38, 1030-1040. http://dx.doi.org/10.1177/0146167212443895 
Guyua, J. M. (1988). La genèse de l'idée de temps [The origin of the idea of time]. In J. A. Michon, V. Pouthas, \& J. L. Jackson (Eds.), Guyau and the idea of time (pp. 37-90). Amsterdam: North Holland. (Original work published 1890).

Hare, C. (2007). Self-bias, time-bias, and the metaphysics of self and time. The Journal of Philosophy, 104, 350-373. https://doi.org/10.5840/jphil2007104717

Hare, C. (2013). Time - The emotional asymmetry. In H. Dyke \& A. Bardon (Eds.), A companion to the philosophy of time (pp 507-520). Chichester, England: John Wiley \& Sons, Ltd.

Hassabis, D., Kumaran, D., \& Maguire, E. A. (2007). Using imagination to understand the neural basis of episodic memory. Journal of Neuroscience, 27, 14365-14374. https://doi.org/10.1523/JNEUROSCI.4549-07.2007

Hayne, H., Gross, J., McNamee, S., Fitzgibbon, O., \& Tustin, K. (2011). Episodic memory and episodic foresight in 3-and 5-year-old children. Cognitive Development, 26, 343355. https://doi:10.1016/j.cogdev.2011.09.006

Holman, E. A., \& Silver, R. C. (1998). Getting 'stuck' in the past: Temporal orientation and coping with trauma. Journal of Personality and Social Psychology, 74, 1146-1163. http://dx.doi.org/10.1037/0022-3514.74.5.1146

Jason, L. A., Schade, J., Furo, L., Reichler, A., \& Brickman, C. (1989). Time orientation: Past, present and future perceptions. Psychological Reports, 64, 1199-1205. https://doi.org/10.2466/pr0.1989.64.3c.1199

Klinger, E., \& Cox, W. M. (1987). Dimensions of thought flow in everyday life. Imagination, Cognition and Personality, 7, 105-128. https://doi.org/10.2190/7K24-G343-MTQW$\underline{115 \mathrm{~V}}$ 
Koch, S. C., Glawe, S., \& Holt, D. V. (2011). Up and down, front and back: Movement and meaning in the vertical and sagittal axes. Social Psychology, 42, 214-224. http://dx.doi.org/10.1027/1864-9335/a000065

Kurtz, J. L., Wilson, T.D., \& Gilbert, D. T. (2007). Quantity versus uncertainty: When winning one prize is better than winning two. Journal of Experimental Social Psychology, 43, 979-985. http://dx.doi.org/10.1016/j.jesp.2006.10.020

Lagattuta, K. H., \& Sayfan, L. (2011). Developmental changes in children's understanding of future likelihood and uncertainty. Cognitive Science, 26, 315-330. http://dx.doi.org/10.1016/j.cogdev.2011.09.004

Lewis, C. C. (1981). How adolescents approach decisions: Changes over grades seven to twelve and policy implications. Child Development, 52, 538-544. http://dx.doi.org/10.2307/1129172

Loewenstein, G. F., Weber, E. U., Hsee, C. K. \& Welch, N. (2001). Risk as feelings. Psychological Bulletin, 127, 267-286. http://dx.doi.org/10.1037/0033-2909.127.2.267 Marghetis, T., Tillman, K, Srinivasan, M., \& Barner, D. (July, 2014). Learning to put time in its place: The development of spatial gestures for time. Sixth Conference of the International Society for Gesture Studies (ISGS), La Jolla, USA.

McColgan K., \& McCormack, T. (2008). Searching and planning: Young children's reasoning about past and future event sequences. Child Development, 79, 1477-1497. http://dx.doi.org/10.1111/j.1467-8624.2008.01200.x

McCormack, T. (2015). The development of temporal cognition. In R. M. Lerner, L. S. Liben, \& U. Mueller, (Eds.), Handbook of child psychology and developmental science, volume 2: Cognitive processes ( $7^{\text {th }}$ ed., Vol. 2, pp. 624-670). Hoboken, New Jersey: Wiley-Blackwell. 
McCormack, T., \& Hanley, M. (2011). Children's reasoning about the temporal order of past and future events. Cognitive Development, 26, 299-314.

http://dx.doi.org/10.1016/j.cogdev.2011.10.001

Miles, L. K., Nind, L. K., \& Macrae, C. N. (2010). Moving through time. Psychological Science, 21, 222-223. http://dx.doi.org/10.1177/0956797609359333

Morewedge, C. K., Gilbert, D. T., \& Wilson, T. D. (2005). The least likely of times: How remembering the past biases forecasts of the future. Psychological Science, 16, 626630. http://dx.doi.org/10.1111/j.1467-9280.2005.01585.x

Nurmi, J. E. (1991). How do adolescents see their future? A review of the development of future orientation and planning. Developmental Review, 11, 1-59. http://dx.doi.org/10.1016/0273-2297(91)90002-6

Okuda, J. (2007). Prospection or projection: Neurobiological bias of stimulus-independent mental travelling. Behavioral and Brain Sciences, 30, 328-329. http://dx.doi.org/10.1017/S0140525X07002142

Parfit, D. (1984). Reasons and persons. Oxford, England: Oxford University Press.

Peters, J., \& Büchel, C. (2011). The neural mechanisms of inter-temporal decision-making: Understanding variability. Trends in Cognitive Sciences, 15, 227-239. https://doi.org.10.1016/j.tics.2011.03.0032

Piaget, J. (1969). The child's conception of time. London, England: Routledge and Keegan Paul.

Preacher, K. J., \& Hayes, A. F. (2008). Asymptotic resampling strategies for assessing and comparing indirect effects in multiple mediator models. Behavior Research Methods, 40, 879-891. https://doi.org/10.3758/BRM.40.3.87

Prencipe, A., Kesek, A., Cohen, J., Lamm, C., Lewis, M. D., Zelazo, P. D. (2011). Development of hot and cool executive function during the transition to adolescence. 
Journal of Experimental Child Psychology, 108, 621-637.

http://dx.doi.org/10.1016/j.jecp.2010.09.008

Quon, E., \& Atance, C. M. (2010). A comparison of preschoolers' memory, knowledge and anticipation of events. Journal of Cognition and Development, 11, 37-60. https://doi.org/10.1080/15248370903453576

Rasmussen, A. S., \& Berntsen, D. (2013). The reality of the past versus the ideality of the future: Emotional valence and functional differences between past and future mental time travel. Memory and Cognition, 41, 187-200. http://dx.doi.org/10.3758/s13421$\underline{012-0260-y}$

Redshaw, J., \& Suddendorf, T. (2016). Children's and apes' preparatory responses to two mutually exclusive possibilities. Current Biology, 26, 1758-1762. https://doi.org.10.1016/j.cub.2016.04.062

Rinaldi, L., Locati, F., Parolin, L., \& Girelli, L. (2017). Distancing the present self from the past and the future: Psychological distance in anxiety and depression. The Quarterly Journal of Experimental Psychology, 70, 1106-1113. http://dx.doi.org/10.1080/17470218.2016.1271443

Roh, S., \& Schuldt, J. P. (2014). Where there's a will: Can highlighting future youth-targeted marketing increase support for soda taxes? Health Psychology, 33, 1610-1613. http://dx.doi.org/10.1037/hea0000021

Rouder, J. N., Speckman, P. L., Sun, D., Morey, R. D., \& Iverson, G. (2009). Bayesian t tests for accepting and rejecting the null hypothesis. Psychonomic Bulletin \& Review, 16, 225-237. https://doi.org/10.3758/PBR.16.2.225

Schacter, D. L., Addis, D. R., Hassabis, D., Martin, V. C., Spreng, R. N., \& Szpunar, K. K. (2012). The future of memory: Remembering, imagining and the brain. Neuron, 76, 677-694. https://doi.org.10.1016/j.neuron.2012.11.001 
Schacter, D. L., Addis, D. R., \& Buckner, R. L. (2007). Remembering the past to imagine the future: The prospective brain. Nature Reviews Neuroscience, 8, 657-661. http://dx.doi.org/10.1038/nrn2213

Seligman, M. E. P., Railton, P., Baumeister, R. F. \& Sripada, C. (2013). Navigating into the future or driven by the past. Perspectives on Psychological Science, 8, 119-141. https://doi.org.10.1177/1745691612474317

Sell, A. J., \& Kaschak, M. P. (2011). Processing time shifts affects the execution of motor responses. Brain and Language, 117, 39-44. http://dx.doi.org/10.1016/j.bandl.2010.07.003

Shipp, A. J., Edwards, J. R., \& Lambert, L. S. (2009). Conceptualization and measurement of temporal focus: The subjective experience of the past, present and future. Organizational Behavior and Human Decision Processes, 110, 1-22. http://dx.doi.org/10.1016/j.obhdp.2009.05.001

Sircova, A., van de Vijver, F. J., Osin, E., Milfont, T. L., Fieulaine, N., Kislali-Erginbilgic, A., Zimbardo, P. G. (2014). A global look at time: A 24-country study of the equivalence of the Zimbardo Time Perspective Inventory. Sage Open, 4, 1-12. http://dx.doi.org/10.1177/2158244013515686

Sircova, A., van de Vijver, F. J., Osin, E., Milfont, T. L., Fieulaine, N., Kislali-Erginbilgic, A., Zimbardo, P. G. (2015). In M. Stolarksi, N. Fieulaine, \& W. Van Beek (Eds.), Time perspective profiles in cultures. Time perspective theory: Review, research, and application (pp. 169-187). Switzerland: Springer International.

Smallwood, J., \& Schooler, J. W. (2015). The science of mind wandering: Empirically navigating the stream of consciousness. Annual Review of Psychology, 66, 487-518. https://doi.org/10.1146/annurev-psych-010814-015331 
Steinberg, L., O’Brien, L., Cauffman, E., Graham, S., Woolard, J., \& Banich, M. (2009). Age differences in future orientation and delay discounting. Child Development, 80, 28-44. http://dx.doi.org/10.1111/j.1467-8624.2008.01244.x

Stites, L. J., \& Özçalışkan, Ş. (2013). Children's developing understanding of different spatial metaphors for time. Journal of Child Language, 40, 1123-1137. http://dx.doi.org/10.1017/S0305000912000384

Stratham, A., Gleicher, F., Boninger, D. S., \& Edwards, C. S. (1994). The consideration of future consequences: Weighing immediate and distant outcomes of behavior. Journal of Personality and Social Psychology, 66, 742-752. http://dx.doi.org/10.1037/0022$\underline{3514.66 .4 .742}$

Suddendorf, T., \& Busby, J. (2005). Making decisions with the future in mind: Developmental and comparative identification of mental time travel. Learning and Motivation, 36, 110-125. http://dx.doi.org/10.1016/j.lmot.2005.02.010

Suddendorf, T., \& Corballis, M. C. (1997). Mental time travel and the evolution of the human mind. Genetic Social and General Psychology Monographs, 123, 133-167. http://dx.doi.org/10.1017/S0140525X07001975

Suddendorf, T., \& Corballis, M. C. (2007). The evolution of foresight: What is mental time travel, and is it unique to humans? Behavioral and Brain Sciences, 30, 299-351. http://dx.doi.org/10.1017/S0140525X07001975

Suhler, C., \& Callender, C. (2012). Thank goodness that argument is over: Explaining the temporal value asymmetry. Philosophers' Imprint, 12, 1-16. http://hdl.handle.net/2027/spo.3521354.0012.0315

Sullivan, M. (in press). Time biases: A theory of rational planning and personal persistence. Oxford, England: Oxford University Press. 
Szpunar, K. K., Chan, J. C. K., \& McDermott, K. B. (2008). Contextual processing in episodic future thought. Cerebral Cortex, 19, 1539-1548. $\underline{\text { http://dx.doi.org/10.1093/cercor/bhn191 }}$

Tarsney, C. (2017). Thank goodness that's Newcomb: The practical relevance of the temporal value asymmetry. Analysis, 77, 750-759. https://doi.org/10.1093/analys/anx108

Tulving, E. (1983). Elements of episodic memory. New York: Oxford University Press.

Van Boven, L., \& Ashworth, L. (2007). Looking forward, looking back: Anticipation is more evocative than retrospection. Journal of Experimental Psychology, 136, 289-300. http://dx.doi.org/10.1037/0096-3445.136.2.289

Van Boven, L., Kane, J., \& McGraw, A. P. (2008). Temporally asymmetric constraints on mental simulation: Retrospection is more constrained than prospection. In K. Markman, W. Klein, \& S. Shur (Eds.), The handbook of imagination and mental simulation (pp. 131-149). Abingdon, England: Routledge.

Van Boven, L., Kane, J., McGraw, A. P., \& Dale, J. (2010). Feeling close: Emotional intensity reduces perceived psychological distance. Journal of Personality and Social Psychology, 98, 872-885. http://dx.doi.org/10.1037/a0019262

Vosgerau, J., Wertenbroch, K., \& Carmon, Z. (2006). Indeterminacy and live television. Journal of Consumer Research, 32, 487-495. http://dx.doi.org/10.1086/500478

Wang, Q., Capous, D., Koh, J. B. K., \& Hou, Y. (2014). Past and future episodic thinking in middle childhood. Journal of Cognition and Development, 15, 625-643. http://dx.doi.org/10.1080/15248372.2013.784977

Wilson, T. D., Centerbar, D. B., Krermer, D. A. \& Gilbert, D. T. (2005). The pleasures of uncertainty: Prolonging positive moods in ways people do not anticipate. Journal of 
Personality and Social Psychology, 88, 5-21. http://dx.doi.org/10.1037/0022$\underline{3514.88 .1 .5}$

Wilson, T. D., \& Gilbert, D. T. (2003). Affective forecasting. In M. Zanna (Ed.), Advances in experimental social psychology, Vol. 35 (pp. 345-411). New York: Elsevier. http://dx.doi.org/10.1016/s0065-2601(03)01006-2

Yehezkel, G. (2014). Theories of time and the asymmetries in human attitudes. Ratio, 27, 6883. https://doi.org/10.1111/rati.12021

Zimbardo, P. G., \& Boyd, J. N. (1999). Putting time in perspective: A valid, reliable individual-differences metric. Journal of Personality and Social Psychology, 77, 1271-1288. http://dx.doi.org/10.1037/0022-3514.77.6.1271 
Table 1. Effect sizes, confidence intervals and JZS Bayes factors in support of the alternative hypothesis for Study 1

\begin{tabular}{|c|c|c|c|c|}
\hline Age group & $\begin{array}{c}\text { Dependent } \\
\text { measure }\end{array}$ & $\begin{array}{c}M D(\text { Future - past }) \\
{[95 \% \mathrm{CI}]}\end{array}$ & $\begin{array}{l}\text { Cohen's } d \\
{[95 \% \mathrm{CI}]}\end{array}$ & $B F_{10}$ \\
\hline \multicolumn{5}{|c|}{ 6-to-7-year-olds } \\
\hline & Emotion & $0.73[0.19,1.28]$ & $0.48[0.12,0.84]$ & 4.48 \\
\hline & Value & $0.35[-0.88,1.59]$ & $0.10[-0.25,0.46]$ & 0.22 \\
\hline & Distance & $-2.69[-3.87,-1.52]$ & $-0.82[-1.19,-0.45]$ & 1335.71 \\
\hline \multicolumn{5}{|l|}{ 9-to-10-year- } \\
\hline \multirow[t]{3}{*}{ olds } & Emotion & $0.65[0.11,1.18]$ & $0.47[0.08,0.86]$ & 2.60 \\
\hline & Value & $0.94[-0.04,1.93]$ & $0.37[-0.02,0.76]$ & 1.02 \\
\hline & Distance & $-2.34[-3.39,-1.3]$ & $-0.88[-1.28,-0.47]$ & 863.92 \\
\hline \multicolumn{5}{|c|}{ 14-to-15-year- } \\
\hline \multirow[t]{3}{*}{ olds } & Emotion & $0.92[0.35,1.49]$ & $0.71[0.26,1.16]$ & 17.48 \\
\hline & Value & $-0.54[-1.23,0.15]$ & $-0.35[-0.78,0.09]$ & 0.66 \\
\hline & Distance & $-2.81[-3.75,-1.87]$ & $-1.32[-1.8,-0.84]$ & 164055.4 \\
\hline \multicolumn{5}{|l|}{ Adults } \\
\hline & Emotion & $0.57[0.23,0.92]$ & $0.52[0.21,0.83]$ & 23.62 \\
\hline & Value & $-0.63[-1.23,-0.04]$ & $-0.33[-0.64,-0.02]$ & 1.29 \\
\hline & Distance & $-2.03[-2.68,-1.37]$ & $-0.96[-1.28,-0.63]$ & 1552231 \\
\hline
\end{tabular}

Note. Pooled estimations of the standard deviations were used in the calculation of Cohen's ds. Effect sizes and confidence intervals were calculated using Exploratory Software for Confidence Intervals (ESCI) (Cumming, 2012). JZS Bayes factors were calculated using an online Bayes factor calculator developed by Rouder, Speckman, Sun, Morey and Iverson (2009). 
Table 2. Effect sizes, confidence intervals and JZS Bayes factors for Study 2A (6-to-7-yearsolds \& 9-to-10-year-olds), Study 2B (14-to-18-year-olds) and Study 3 (4-to-5-year-olds)

\begin{tabular}{lllll}
\hline \multicolumn{1}{c}{ Age group } & $\begin{array}{c}\text { Dependent } \\
\text { measure }\end{array}$ & $\begin{array}{c}M D(\text { Future - past }) \\
{[95 \% \mathrm{CI}]}\end{array}$ & $\begin{array}{c}\text { Cohen's } d \\
{[95 \% \mathrm{CI}]}\end{array}$ & \multicolumn{1}{c}{$B F_{10}$} \\
\hline 6-to-7-year-olds & & & & \\
(Study 2a) & Emotion & $0.78[0.19,1.37]$ & $0.5[0.12,0.88]$ & 4.01 \\
& Value & $0.11[-1.28,1.49]$ & $0.03[-0.34,0.4]$ & 0.20 \\
& Distance & $-3.15[-4.34,-1.95]$ & $-0.98[-1.37,-0.59]$ & 15062.85 \\
\hline 9-to-10-year-olds & & & & \\
(Study 2a) & Emotion & $0.46[0.04,0.88]$ & $0.40[0.03,0.77]$ & 1.56 \\
& Value & $1.33[0.29,2.38]$ & $0.47[0.1,0.84]$ & 3.32 \\
& Distance & $-2.87[-3.82,-1.91]$ & $-1.11[-1.5,-0.71]$ & 325587.7 \\
\hline 14-to-18-year- & & & & \\
olds (Study 2b) & Emotion & $0.80[0.57,1.03]$ & $0.54[0.39,0.7]$ & 660225301 \\
& Value & $0.57[0.32,0.82]$ & $0.35[0.2,0.51]$ & 1783.02 \\
& Distance & $-3.00[-3.36,-2.64]$ & $-1.26[-1.43,-1.09]$ & $1.71 \mathrm{e}^{46}$ \\
\hline 4-to-5-year-olds & & & & \\
(Study 3) & Emotion & $0.22[-0.14,0.57]$ & $0.14[-0.09,0.38]$ & 0.26 \\
& Distance & $-1.31[-2.14,-0.48]$ & $-0.38[-0.61,-0.14]$ & 12.50 \\
\hline
\end{tabular}



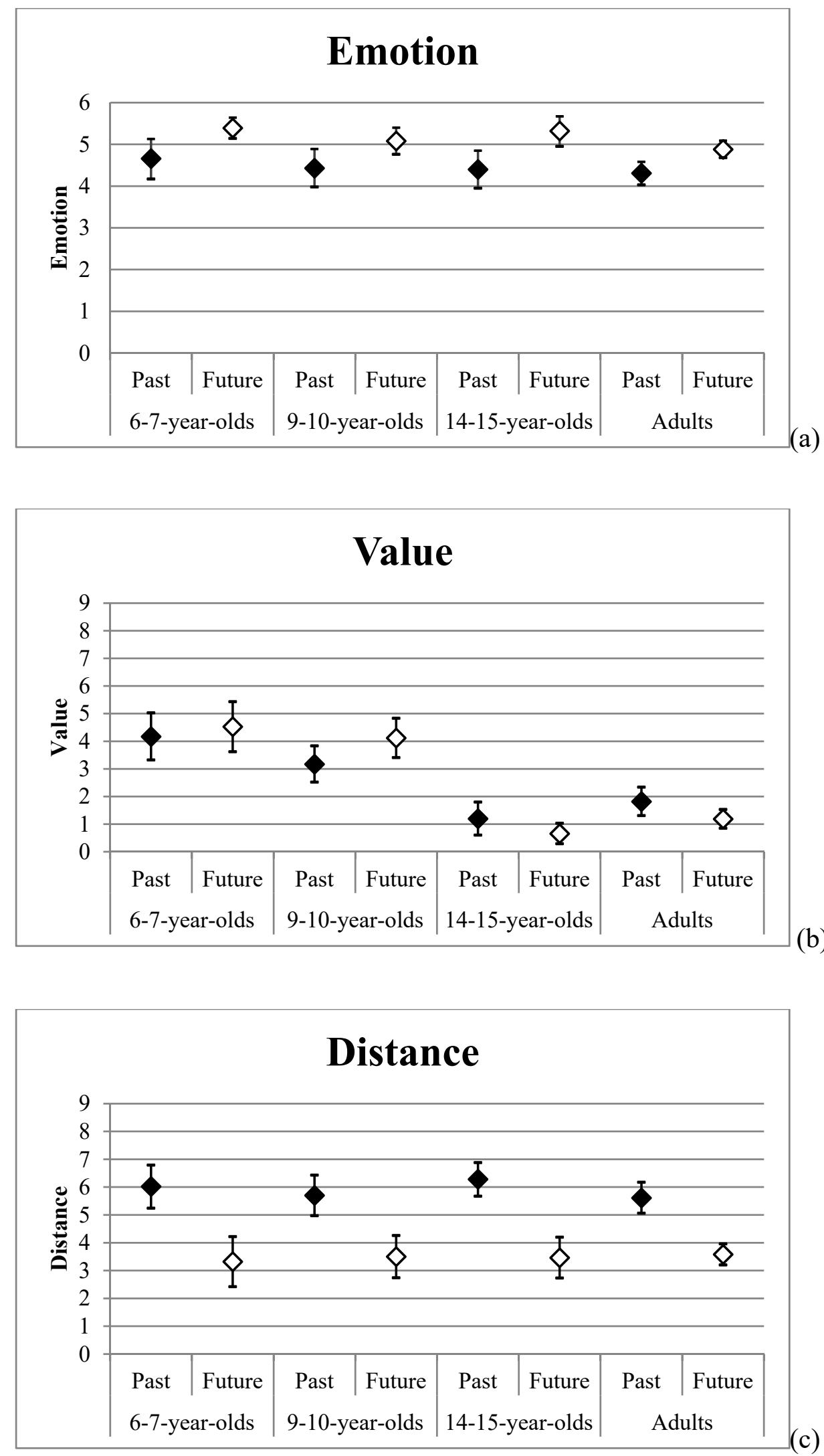

Figure $1 a, 1 b \& 1 c$. Results from Study 1: mean emotion, value, and distance ratings by age group and temporal condition. Please note that value judgments by children were made on a 
different scale to the scale used by adolescents and adults, although for both sets of participants the scores are plotted on a 10-point scale. Error bars represent $95 \%$ confidence intervals.
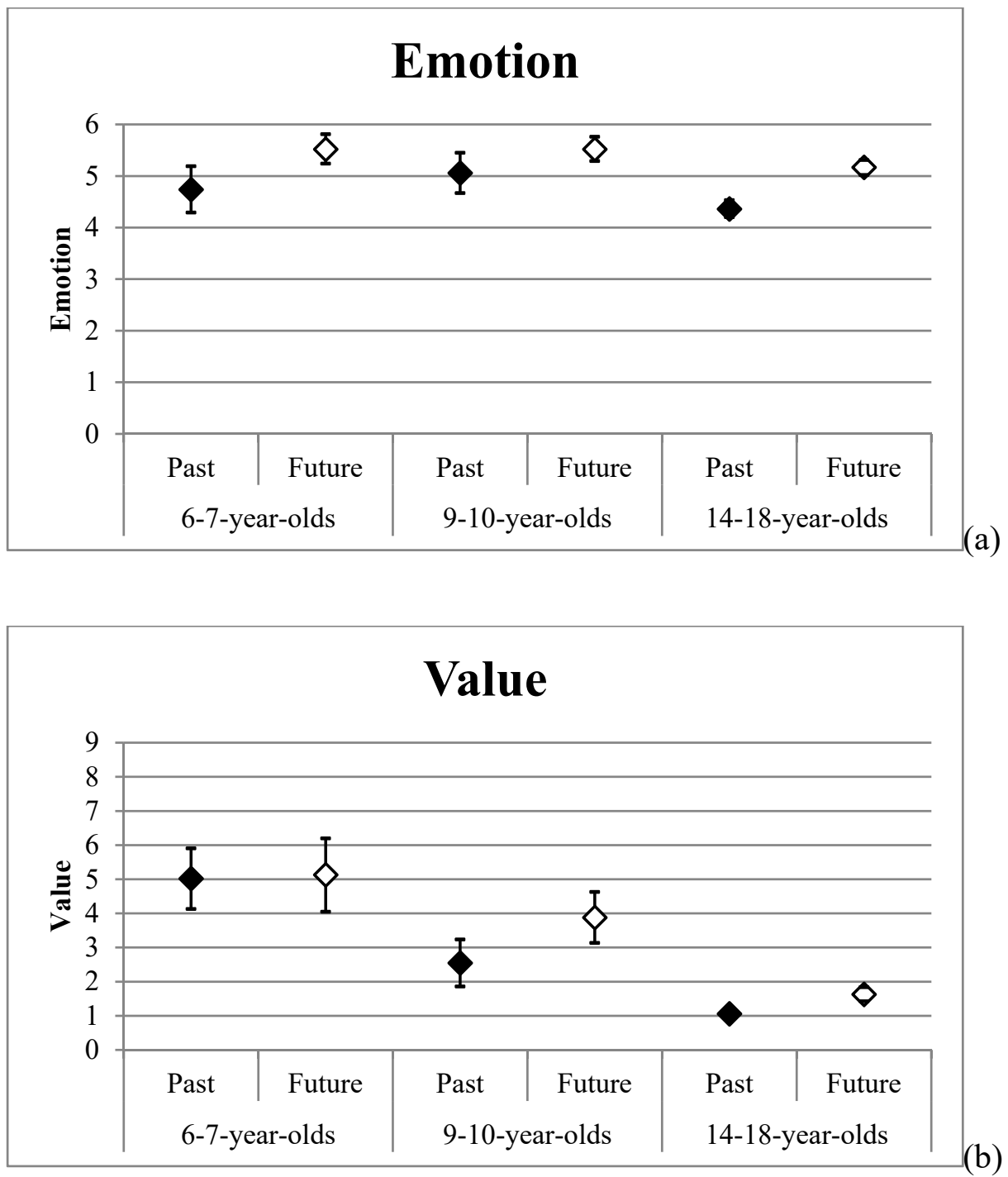


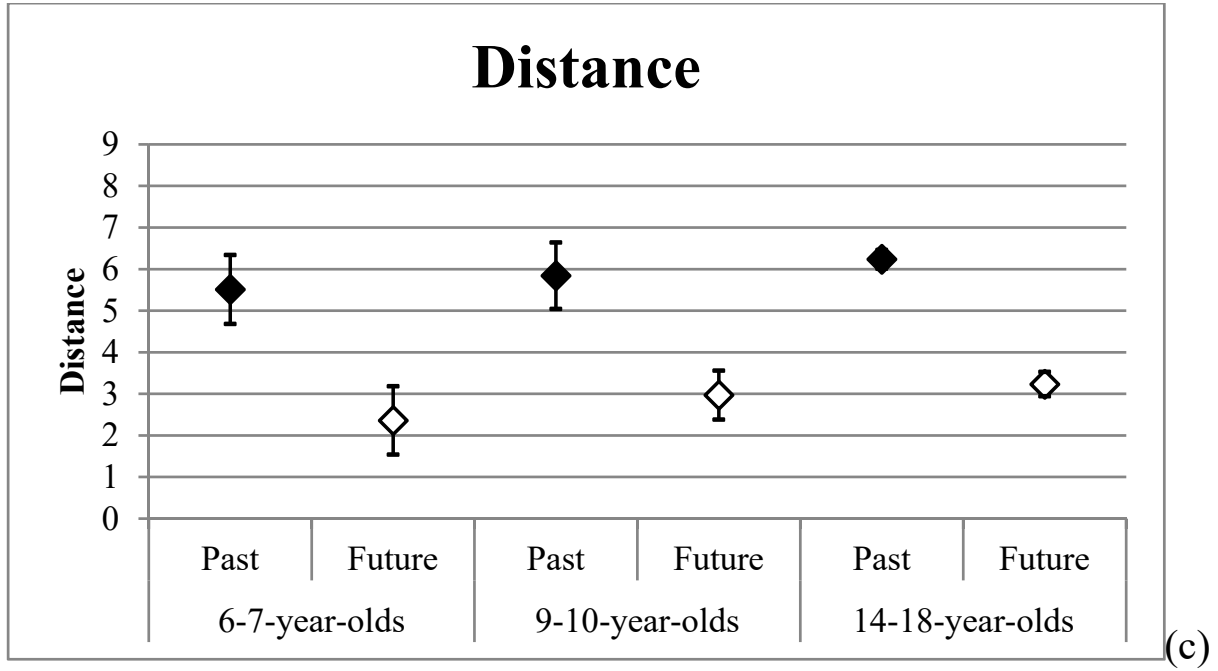

Figure $2 a, 2 b \& 2 c$. Results from Study 2: mean emotion, value, and distance ratings by age group and temporal condition. The value judgments of children were made on a different scale to the scale used by adolescents, although both are plotted on a 10-point scale. Error bars represent $95 \%$ confidence intervals.

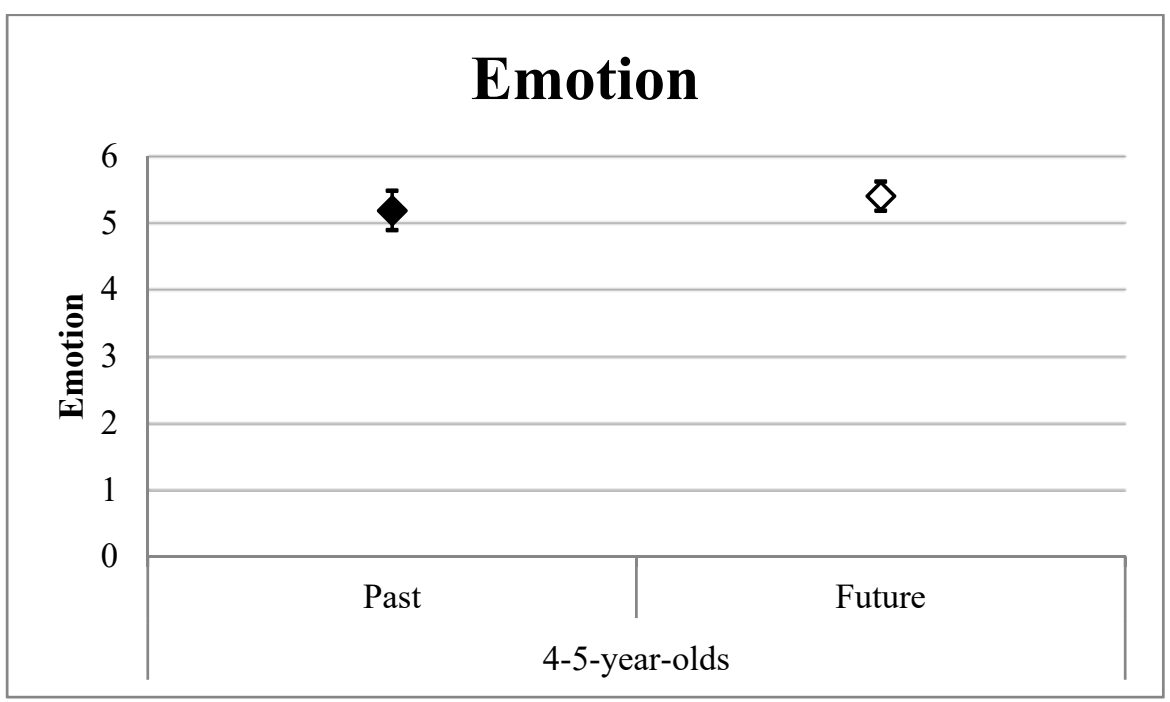




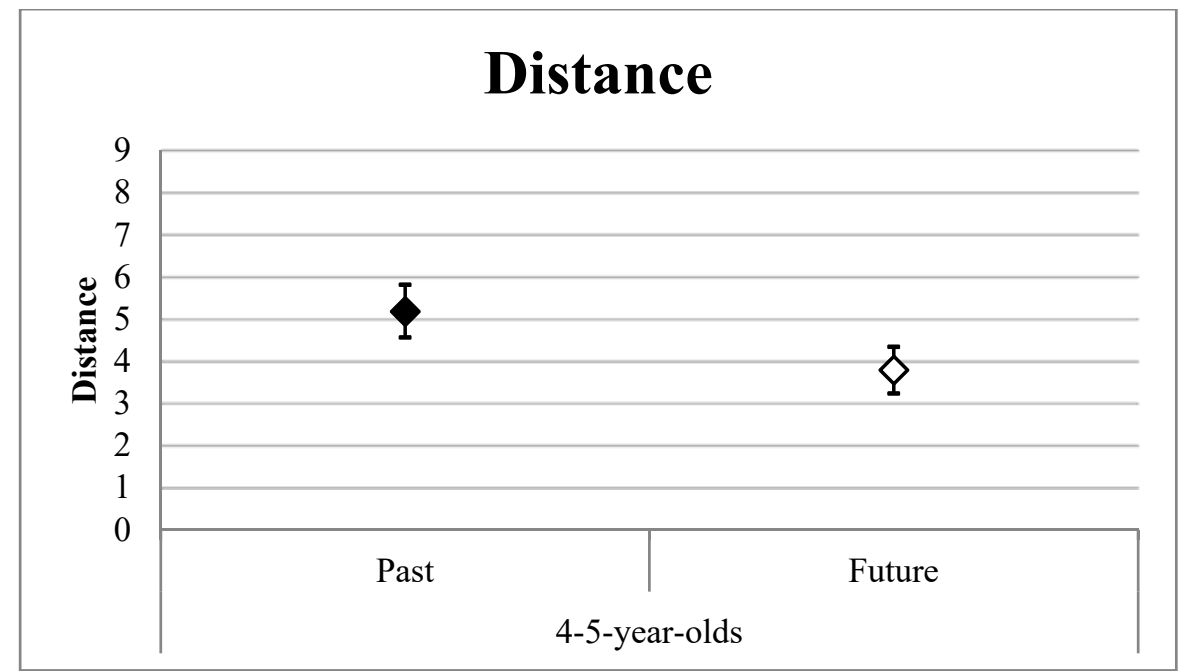

Figure $3 a \& 3 b$. Results from Study 3: mean emotion and distance ratings by temporal condition of 4-to-5-year-olds. Error bars represent 95\% confidence intervals. 